\title{
Final Report for the Initial Solid Phase Characterization of the 2011 Grab Samples and Composite for the C-109 Hard Heel Study
}

\author{
Jason S. Page \\ Gary A. Cooke \\ John A. Pestovich \\ Washington River Protection Solutions LLC
}

December 2011

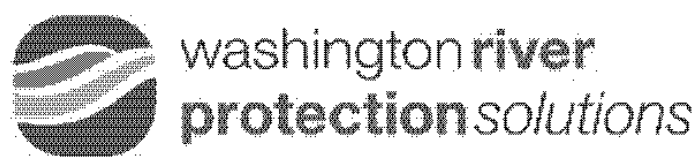

Prepared for the U.S. Department of Energy

Office of River Protection

Contract No. DE-AC27-08RV14800 


\section{LAB-RPT-11-00009 REV 0}

\section{EXECUTIVE SUMMARY}

On May 3, 2011, solid phase characterization subsamples were taken from six of the eight grab samples that had been collected from tank 241-C-109 in April, 2011 and delivered to the 222-S Laboratory. These subsamples were characterized in order to guide the creation of the composite for the $\mathrm{C}-109$ hard heel study. Visual observation showed that there was a large variability in the physical characteristics of the eight individual grab samples. Several of the grab samples consisted of 'stone-like' cobbles (several $>25 \mathrm{~mm}$ in diameter) while the other grab samples were of a finer granular composition referred to as 'bulk material.' Half of the six subsamples taken for this initial SPC were of crushed cobbles and half were of the bulk material. Scanning electron microscopy was performed on all six subsamples, and X-ray diffraction was performed on all three of the 'bulk material' samples and one of the crushed cobble samples.

The crushed cobbles were found to be composed primarily of gibbsite $\left(\mathrm{Al}[\mathrm{OH}]_{3}\right)$. Analysis by $\mathrm{X}$-ray diffraction indicated gibbsite to be the only crystalline phase detected, and scanning electron microscopy showed the crushed cobbles to consist primarily of aggregates of euhedral to subhedral gibbsite crystals that were 20 to $100 \mu \mathrm{m}$ in size. The aggregates, having a moderate amount of pore space, were cemented primarily by recrystallized gibbsite making them resistant to crushing.

The bulk material consisted of coarse to fine-grained pebble-sized ( 2 to $20 \mathrm{~mm}$ ) particles. The $\mathrm{X}$-ray diffraction analysis showed them to be a mixture of natrophosphate $\left(\mathrm{Na}_{7}\left[\mathrm{PO}_{4}\right]_{2} \mathrm{~F} \cdot 19\left[\mathrm{H}_{2} \mathrm{O}\right]\right)$ and gibbsite crystals in varying amounts in each of the three subsamples (i.e., some grab samples were primarily natrophosphate while others were mixed with gibbsite). The scanning electron microscopy analysis of the bulk material showed the crystals to be euhedral to anhedral (rounded) in shape.

Trace phases, too minor to be detected by XRD, were observed in the SEM analysis of both the crushed cobble and bulk material. Some of the trace phases were identified as uranium-rich (sodium diuranate and/or clarkeite), sodium aluminum-rich (dawsonite and/or sodium aluminate), and a sludge-like phase with a variable chemistry rich in iron, nickel, and lead.

A composite was created from the grab samples and a sample was taken from the composite, labeled S11T009482, for solid phase characterization. In general, the vast majority of the particles and aggregates analyzed in the composite were either gibbsite or natrophosphate. A very minor phase consisting of dispersed small particles was rich in uranium. 
Table of Contents

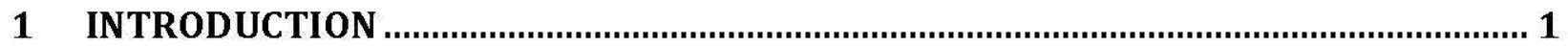

2 SCANNING ELECTRON MICROSCOPY ANALYSIS PARAMETERS............................... 3

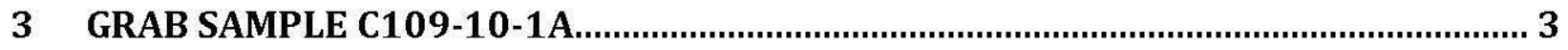

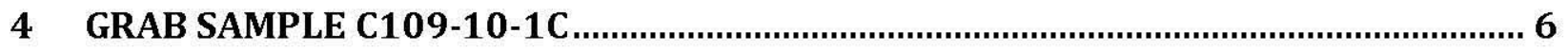

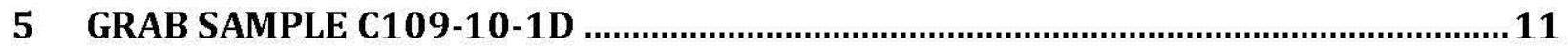

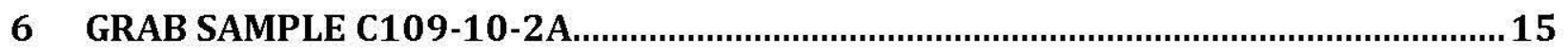

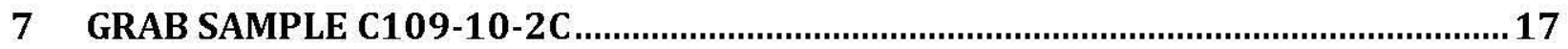

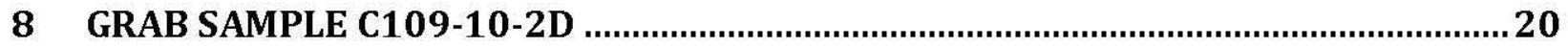

9 COMPOSITE

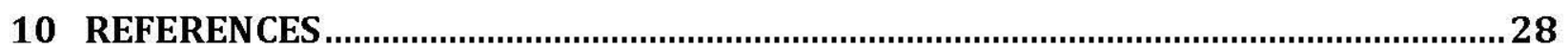

\section{List of Tables}

Table 1. Subsampling and SPC Experiments of the Eight Grab Samples. ...............................2

\section{List of Figures}

Figure 1. Photographs of the Tank Solids Grab Samples Taken from Tank C-109..................1

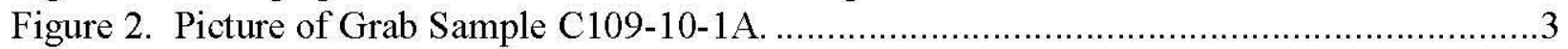

Figure 3. XRD Analysis of S1 1T006062 .................................................................. 4

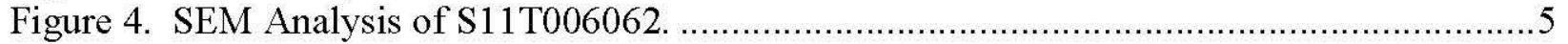

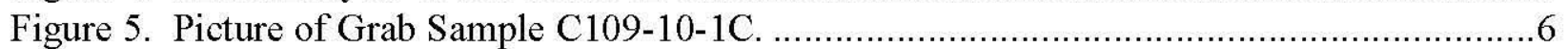

Figure 6. Picture of Grab Sample C109-10-1C after Crushing. ........................................... 7

Figure 7. XRD Analysis of S1 1T006064 Crushed Cobble. ...............................................

Figure 8. SEM Analysis of S11T006064 Showing Gibbsite as the Primary Phase.....................9

Figure 9. SEM Analysis of S11T006064 Highlighting the Aggregate Cementation..................9

Figure 10. Other Phases Serving to Cement the Aggregates............................................. 10

Figure 11. SEM Analysis of S11T00604 Showing a Uranium-Rich Phase...........................11

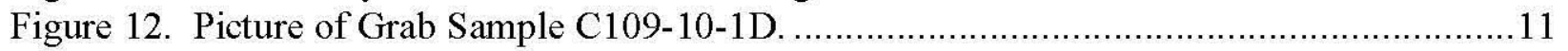




\section{LAB-RPT-11-00009 REV 0}

Figure 13. XRD Analysis of S1 1T006065 ............................................................. 12

Figure 14. SEM Analysis of a Selected Gibbsite Particle from S11T006065 Bulk Material. .....13

Figure 15. SEM Analysis of a Selected Natrophosphate Particle from S11T006065 ..............14

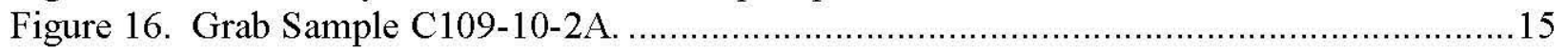

Figure 17. SEM Analysis of S11T006066 Crushed Cobble............................................. 16

Figure 18. SEM Analysis of an Iron-Rich Sludge Trace Phase............................................ 16

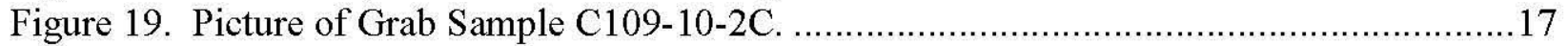

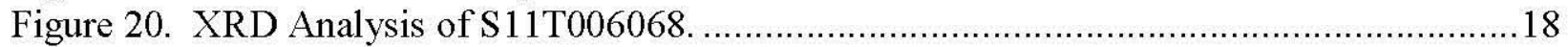

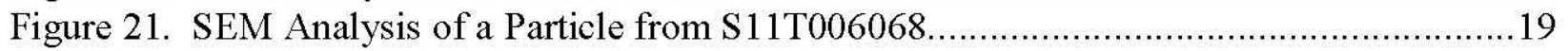

Figure 22. SEM Analysis of a Sodium Diuranate Trace Phase..........................................19

Figure 23. Picture of Grab Sample C109-10-2D. ............................................................20

Figure 24. SEM Analysis of S11T006069 Showing Gibbsite Aggregate.............................21

Figure 25. SEM Analysis of S11T006069 Showing Partially Dissolved Natrophosphate.........21

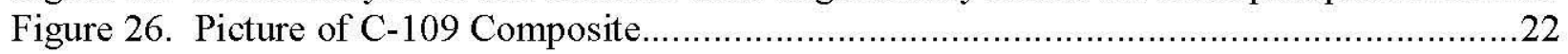

Figure 27. XRD Analysis of S11T009482 Composite ..............................................23

Figure 28. SE and BSE Images Showing Particle Size and Relative Elemental Mass..............24

Figure 29. SE Images and EDS Spectra of Various Particles. .........................................25

Figure 30. SE Images and EDS Spectra of Various Smaller Particles....................................27

Figure 31. BSE Image and EDS Spectrum of a Minor Uranium-Rich Phase. ........................28

\section{Abbreviations and Acronyms}

\section{List of Terms}

ATL Advanced Technologies and Laboratories International, Inc.

BSE backscatter electron

C-109 tank 241-C-109

EDS energy dispersive X-ray spectrometry

PSEM personal scanning electron microscope

SE secondary electron

SEM scanning electron microscopy

SPC solid phase characterization

XRD X-ray diffraction

Units

g gram

$\mathrm{ml} \quad$ milliliter

$\mathrm{mm} \quad$ millimeter

$\mu \mathrm{m} \quad$ micrometer 


\section{LAB-RPT-11-00009 REV 0}

\section{INTRODUCTION}

As described in the tank sampling and analysis plan, RPP-PLAN-47927, Sampling and Analysis Plan for Waste Solids in Tank 241-C-109 After Sluicing, tank 241-C-109 (C-109) was sampled in order to perform chemical and radiochemical analyses, physical characterization, and retrieval (dissolution) testing on waste solids retrieved from the bottom of the tank. The testing procedures, described in ATS-LAB-PLN-11-00006, Test Plan for Tank 241-C-109 Heel Solids Characterization, and Dissolution Testing, included initial subsampling and solid phase characterization (SPC) experiments to guide the creation of one or more composites to be used for the bulk of the study. The Process Chemistry group personnel at the 222-S Laboratory performed the initial SPC analyses (summarized in this report), and Advanced Technologies and Laboratories, International, Inc. (ATL) personnel performed the initial chemical and radiological analyses as reported in RPP-RPT-50883, Final Report for the Analysis of Waste Solids in Tank 241-C-109.

Visual observation of the eight grab samples from C-109 showed that there was a large variability in the physical characteristics. All pictures of the grab samples and C-109 composite were taken in the 11A hot cell by ATL personnel, and Figure 1 shows all eight of the grab samples moderately dispersed on individual, labeled trays. Some of the grab samples consisted solely of 'stone-like' cobbles (some $>25 \mathrm{~mm}$ in diameter), others were of a finer granular composition (referred to as 'bulk material'), and others were a mix of the two.

Figure 1. Photographs of the Tank Solids Grab Samples Taken from Tank C-109.

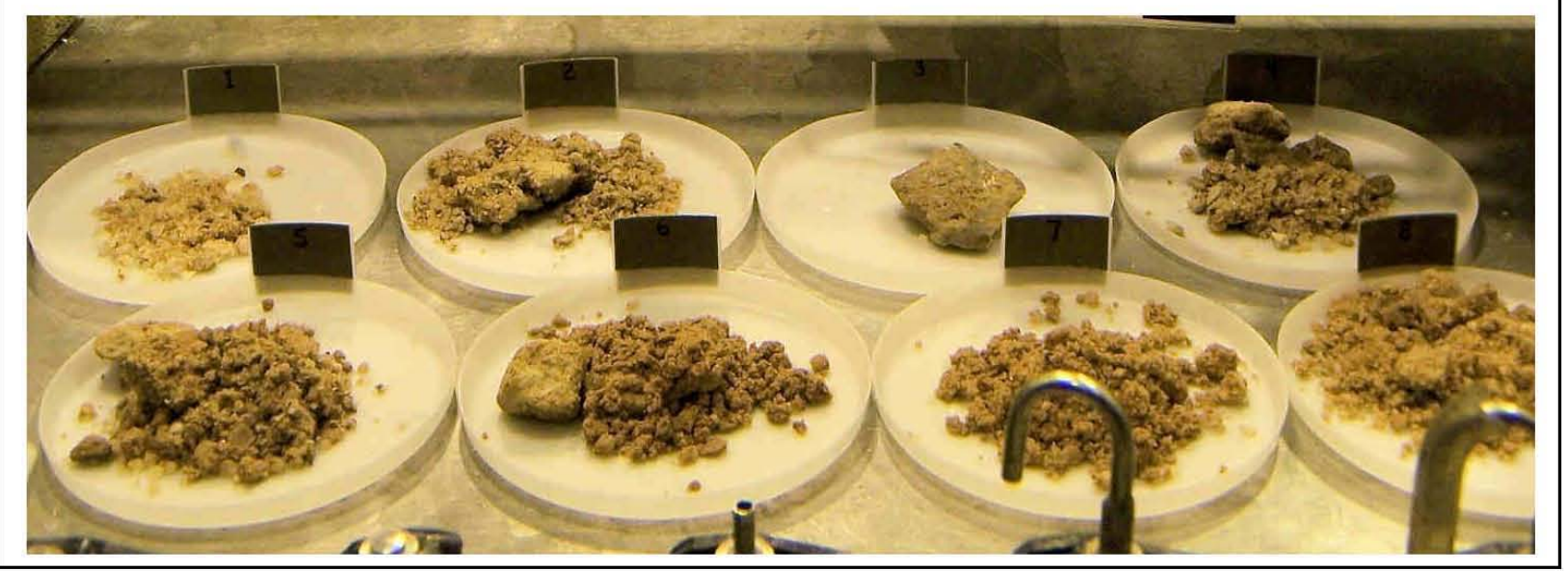

Subsamples were taken from six of the eight grab samples to perform SPC experiments to obtain information on chemical content, particle size/structure, and phase composition (Table 1). Half of the six samples taken for this initial SPC were selected from crushed cobbles and half were taken from the bulk material. Scanning electron microscopy (SEM) was performed on all six samples, and X-ray Diffraction (XRD) was performed on the three 'bulk material' samples and one of the crushed cobble samples. After the initial SPC of the eight original grab samples from C-109, a single composite was created and homogenized. From this single composite, a sample was taken and submitted for additional SPC. 
LAB-RPT-11-00009 REV 0

Table 1. Subsampling and SPC Experiments of the Eight Grab Samples.

\begin{tabular}{|c|c|c|c|c|c|}
\hline Sample ID & Tray \# & $\begin{array}{c}\text { Solid Weight }{ }^{\text {a }} \\
\text { (g) }\end{array}$ & $\begin{array}{c}\text { Lab Sample } \\
\text { ID for } \\
\text { Subsample }\end{array}$ & $\begin{array}{c}\text { Visual } \\
\text { Characterization }\end{array}$ & $\begin{array}{c}\text { SPC } \\
\text { Analyses } \\
\text { Performed }\end{array}$ \\
\hline C109-10-1A & 1 & 53.4 & S11T006062 & $\begin{array}{l}\text { Coarse, dry, light- } \\
\text { colored solids } \\
\text { (bulk sample) }\end{array}$ & SEM \& XRD \\
\hline C109-10-1B & 2 & 257.3 & $\begin{array}{c}\text { not } \\
\text { subsampled }\end{array}$ & $\begin{array}{c}\text { A large piece } \\
\text { broken up with } \\
\text { mortar and pestle } \\
\text { and coarse solids }\end{array}$ & NA \\
\hline C109-10-1C & 3 & 104.4 & S11T006064 & $\begin{array}{l}\text { Single large piece } \\
\text { broken up with } \\
\text { mortar and pestle } \\
\text { (crushed cobble) }\end{array}$ & SEM \& XRD \\
\hline C109-10-1D & 4 & 214.6 & S11T006065 & (bulk sample) & SEM \& XRD \\
\hline C109-10-2A & 5 & 279.0 & S11T006066 & $\begin{array}{c}\text { A small piece } \\
\text { broken up with } \\
\text { mortar and pestle } \\
\text { (crushed cobble) }\end{array}$ & SEM \\
\hline C109-10-2B & 6 & 203.4 & $\begin{array}{c}\text { not } \\
\text { subsampled }\end{array}$ & $\begin{array}{l}\text { Coarse solids } \\
\text { (bulk sample) }\end{array}$ & NA \\
\hline C109-10-2C & 7 & 186.8 & S11T006068 & $\begin{array}{l}\text { Coarse solids } \\
\text { (bulk sample) }\end{array}$ & SEM \& XRD \\
\hline C109-10-2D & 8 & 176.7 & S11T006069 & $\begin{array}{c}\text { Coarse solids } \\
\text { (crushed cobble) }\end{array}$ & SEM \\
\hline
\end{tabular}

${ }^{a}$ Solid weights from RPP-RPT-50883 Table 1 


\section{LAB-RPT-11-00009 REV0}

\section{SCANNING ELECTRON MICROSCOPY ANALYSIS PARAMETERS}

SEM analysis was conducted using an Aspex Personal Scanning Electron Microscope (PSEM) in Room 1-A. The PSEM is equipped with a light element energy dispersive X-ray spectrometer (EDS) system for chemical analysis. The instrument was operated at an accelerating voltage of $20 \mathrm{kV}$, and the samples were mounted at a working distance of 20 to $25 \mathrm{~mm}$. The images were acquired in secondary electron(SE) and backscatter electron (BSE) modes. The EDS spectra were acquired for 30 seconds live time (unless noted) on relatively smooth surfaces (either flat or sloping toward the detector) near the center of the image.

\section{GRAB SAMPLE C109-10-1A}

The three "bulk samples' selected for SEM and XRD analysis consisted of coarse and finegravel. Sample S11T006062 was made from grab sample C109-10-1A (Figure 2). In the hot cell examination, it appeared to have a greater amount of clear, natrophosphate $\left(\mathrm{Na}_{7} \mathrm{~F}\left[\mathrm{PO}_{4}\right]_{2}-19 \mathrm{H}_{2} \mathrm{O}\right)$ crystals. The XRD aralysis provided confirmation that S11 T006062 is rich in natrophosphate as that was the only crystalline compound detected (Figure 3). The relative percent composition was found to be $100 \%$ ratrophosphate which is a relative amount based upon all the crystalline species present in the sample. Several mounted particles were subject to SEM aralysis, and the EDS analysis detected sodium fluoride phosphate, reaffiming it to be natrophosphate. A representative particle, $2-3 \mathrm{~mm}$ in diameter and subhedral with rounded edges, is shown in Figure 4. The corresponding EDS spectrum was taken from the spot marked with a small, yellow cross in the expanded image. Trace amounts of sodium and aluminum-rich phases were observed as patches and coatings on the sodium fluoride phosphate phase.

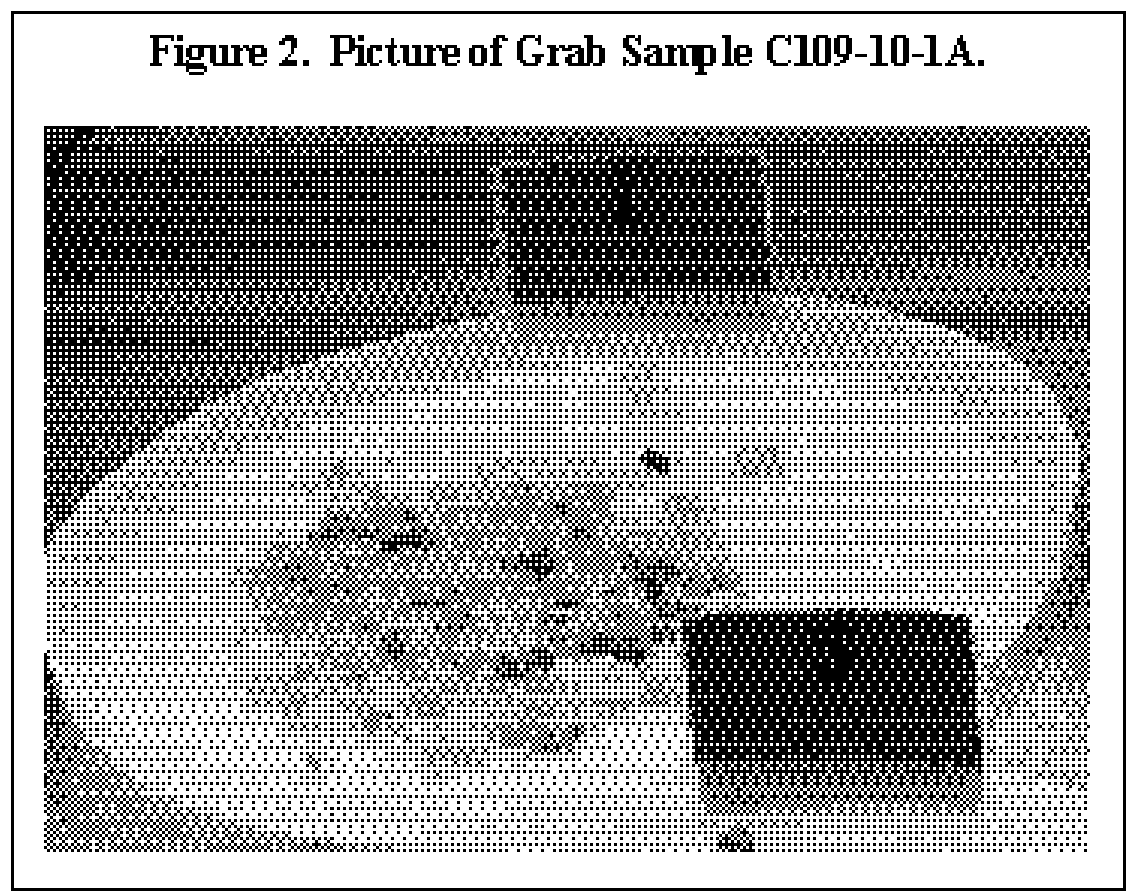


LAB-RPT-11-00009 REV 0

Figure 3. XRD Analysis of S11T006062.

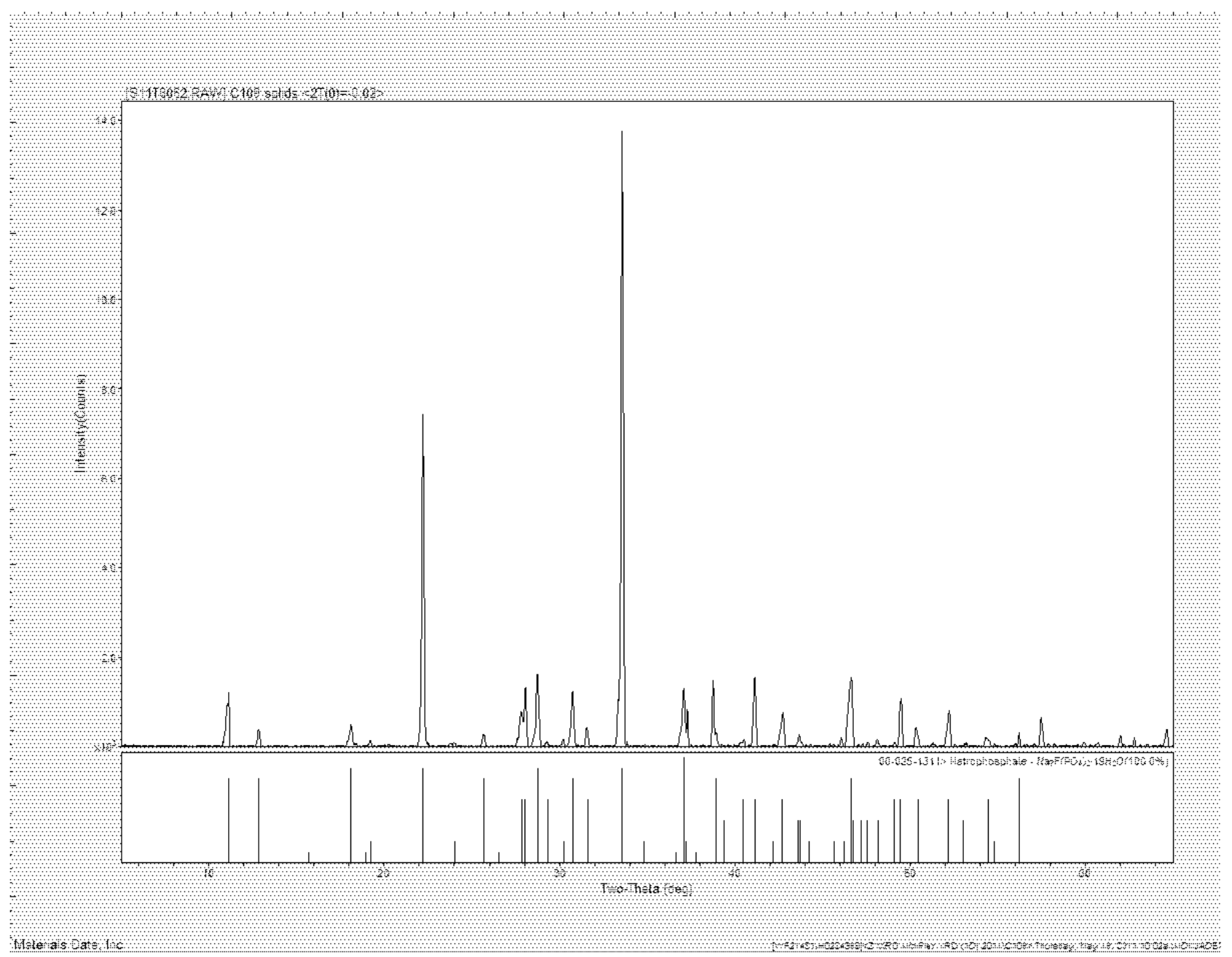


Figure 4. SEM Analysis of S11T006062.
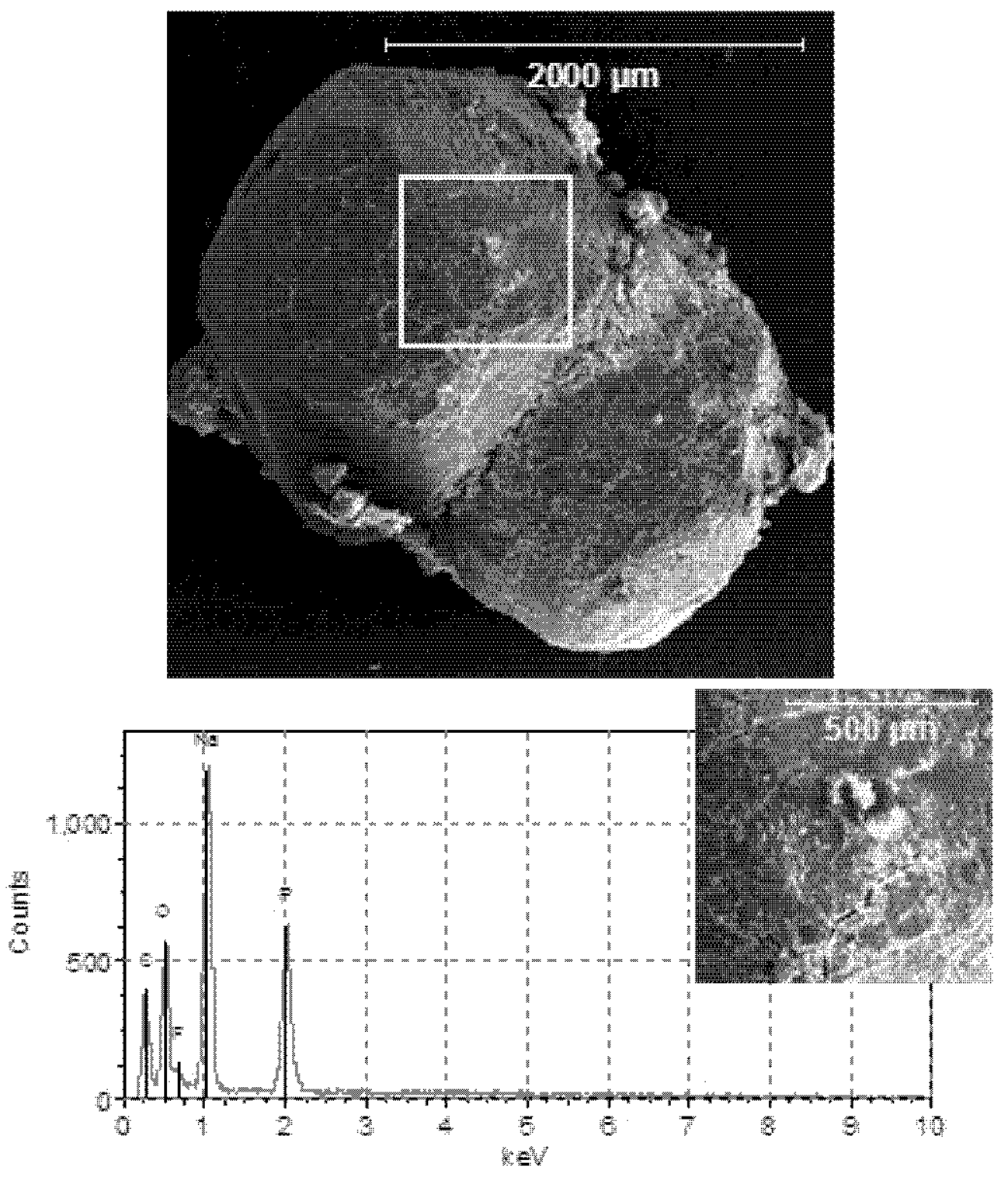


\section{LAB-RPT-11-00009 REV 0}

\section{GRAB SAMPLE C109-10-1C}

A picture of the large cobble that made up grab sample C109-10-1C is shown in Figure 5. This cobble was broken up using a mortar and pestle. Moderate to heavy force by the manipulator was required to break up the cobble (Figure 6). A portion of the crushed cobble was subsampled for SPC and labeled S11T006064. The XRD analysis of the sample showed that gibbsite $\left(\mathrm{Al}[\mathrm{OH}]_{3}\right.$ ) was the only crystalline phase detected (Figure 7 ). The percent composition was found to be $100 \%$ gibbsite which is a relative amount based upon all the crystalline phases present in the sample. The SEM examination of pieces of the crushed cobble showed that they consist primarily of aggregates of euhedral to subhedral gibbsite crystals, dominantly in the 20 to $100 \mu \mathrm{m}$ size range. Figure 8 shows an SEM image of one of the fragments with the EDS spectrum taken from the spot marked with the yellow '+'. The gibbsite crystals in the cobblesized aggregates appear to be cemented primarily by recrystallized gibbsite. In other words, the boundaries between grains are mainly aluminum-rich. Gibbsite cementation and overgrowths like this would make the cobbles resistant to crushing. However, some cementation by trace amounts of dawsonite (sodium aluminum carbonate hydroxide), sodium aluminate, thermonatrite (sodium carbonate), or other sodium-rich phases was also occurring. For example, Figure 9 shows a sodium-bearing phase cementing the gibbsite grains together.

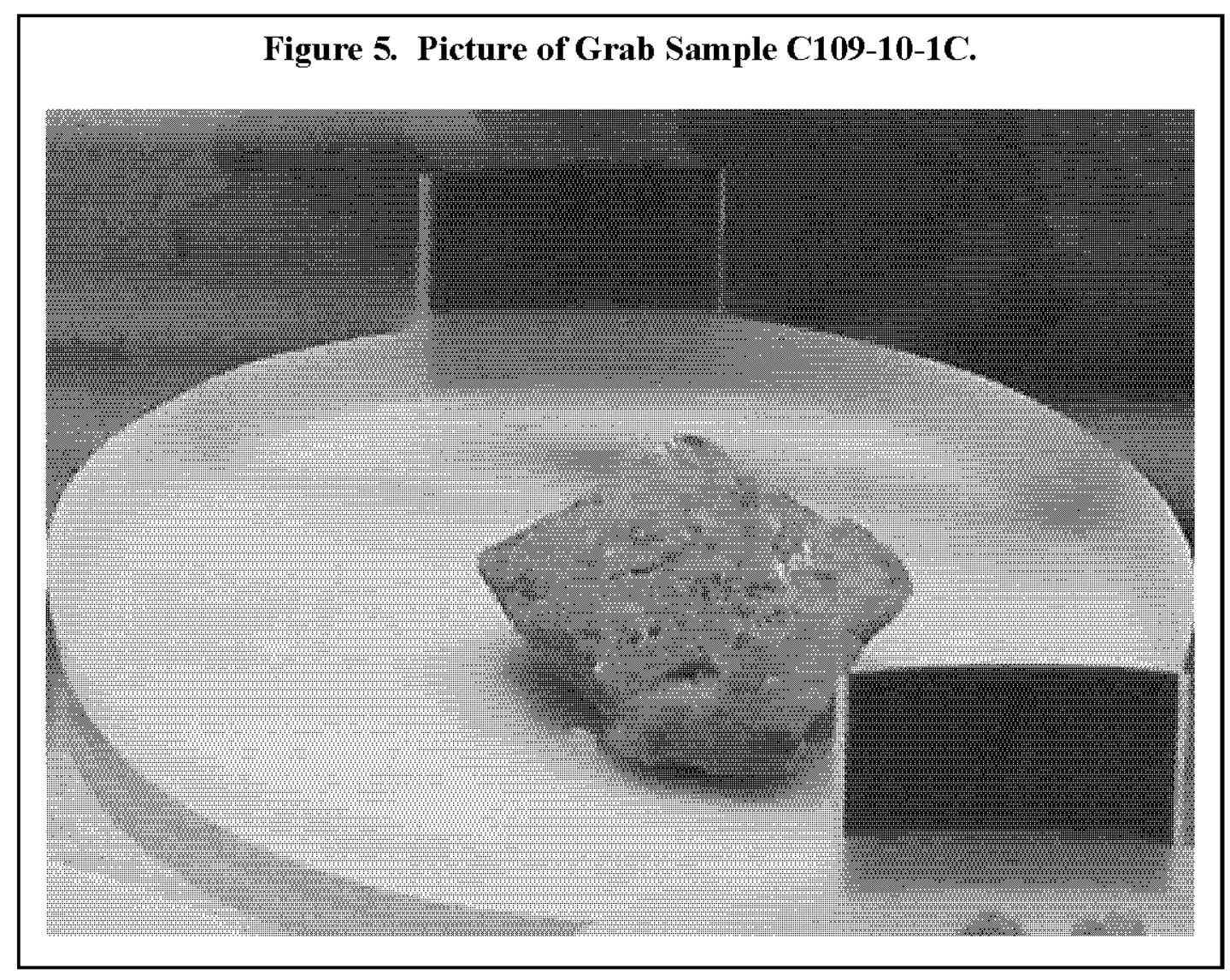


Figure 6. Picture of Grab Sample C109-10-1C after Crushing.

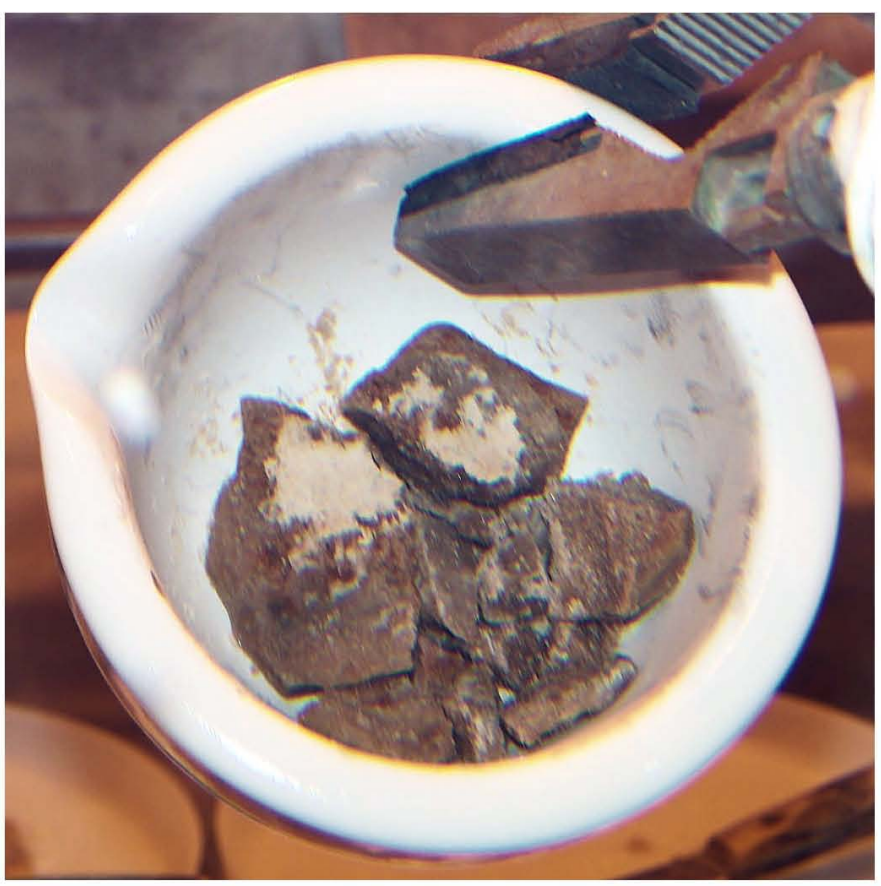


LAB-RPT-11-00009 REV 0

Figure 7. XRD Analysis of S11T006064 Crushed Cobble.

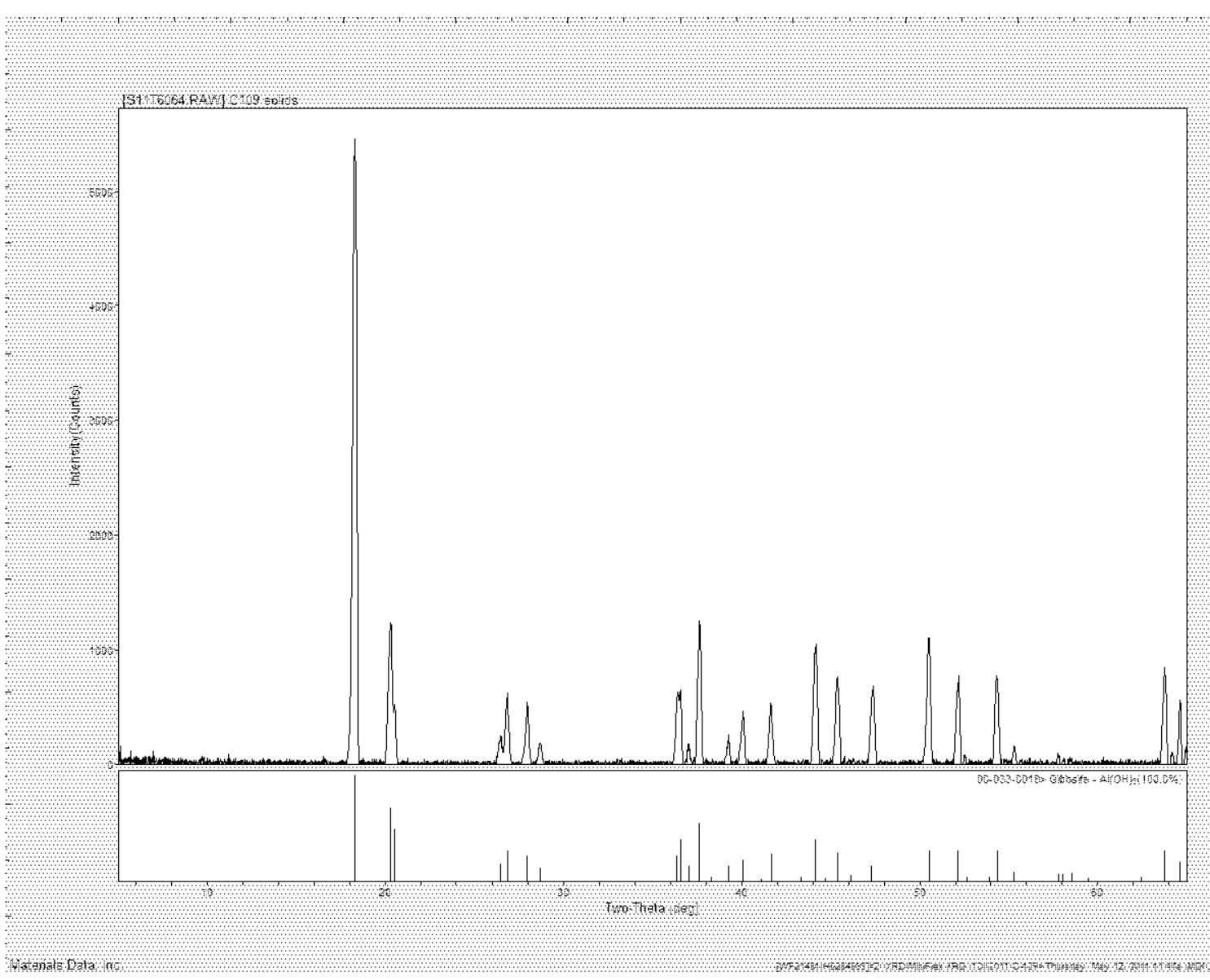


Figure 8. SEM Analysis of S11T006064 Showing Gibbsite as the Primary Phase.
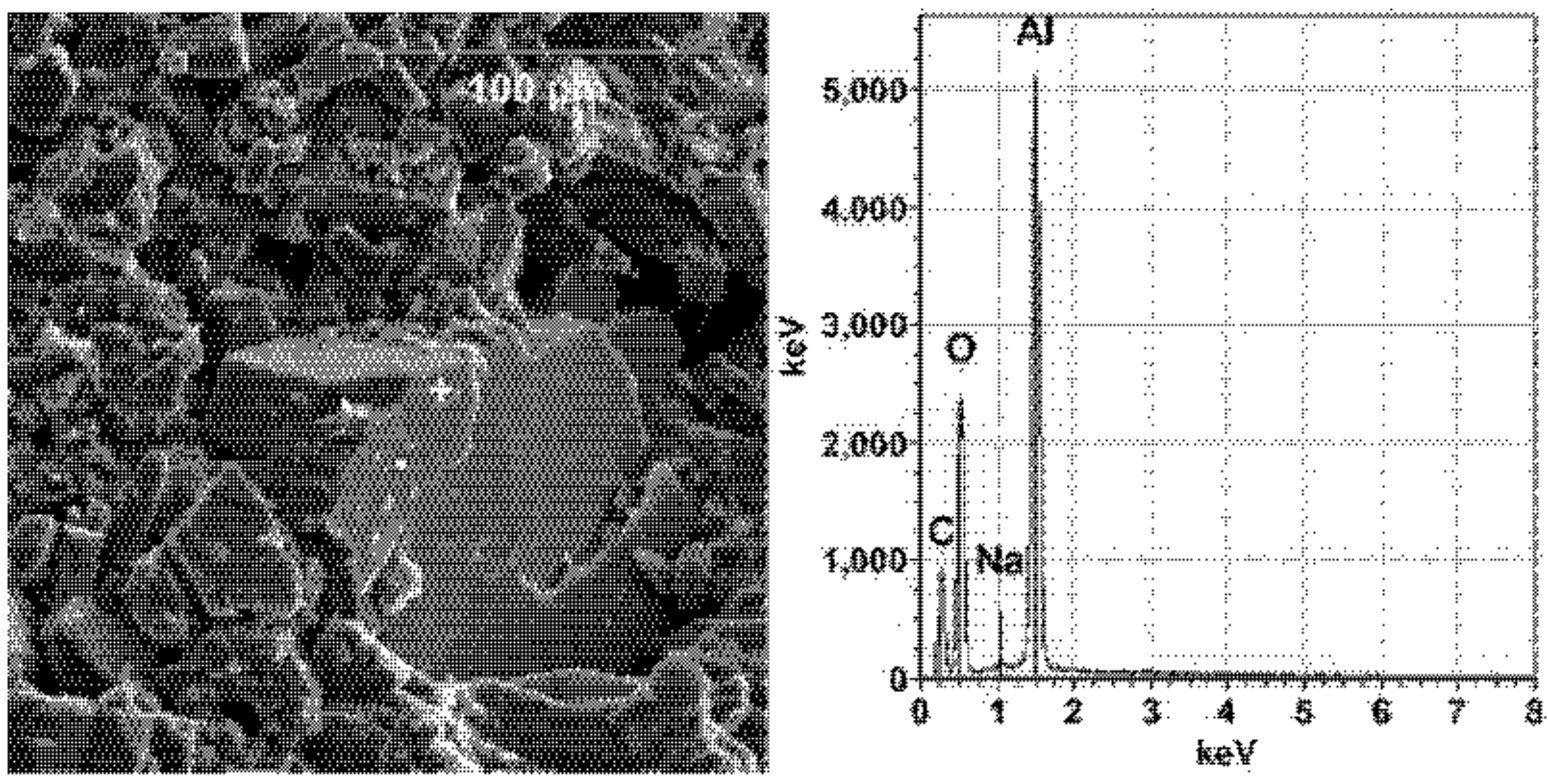

Figure 9. SEM Analysis of S11T006064 Highlighting the Aggregate Cementation.
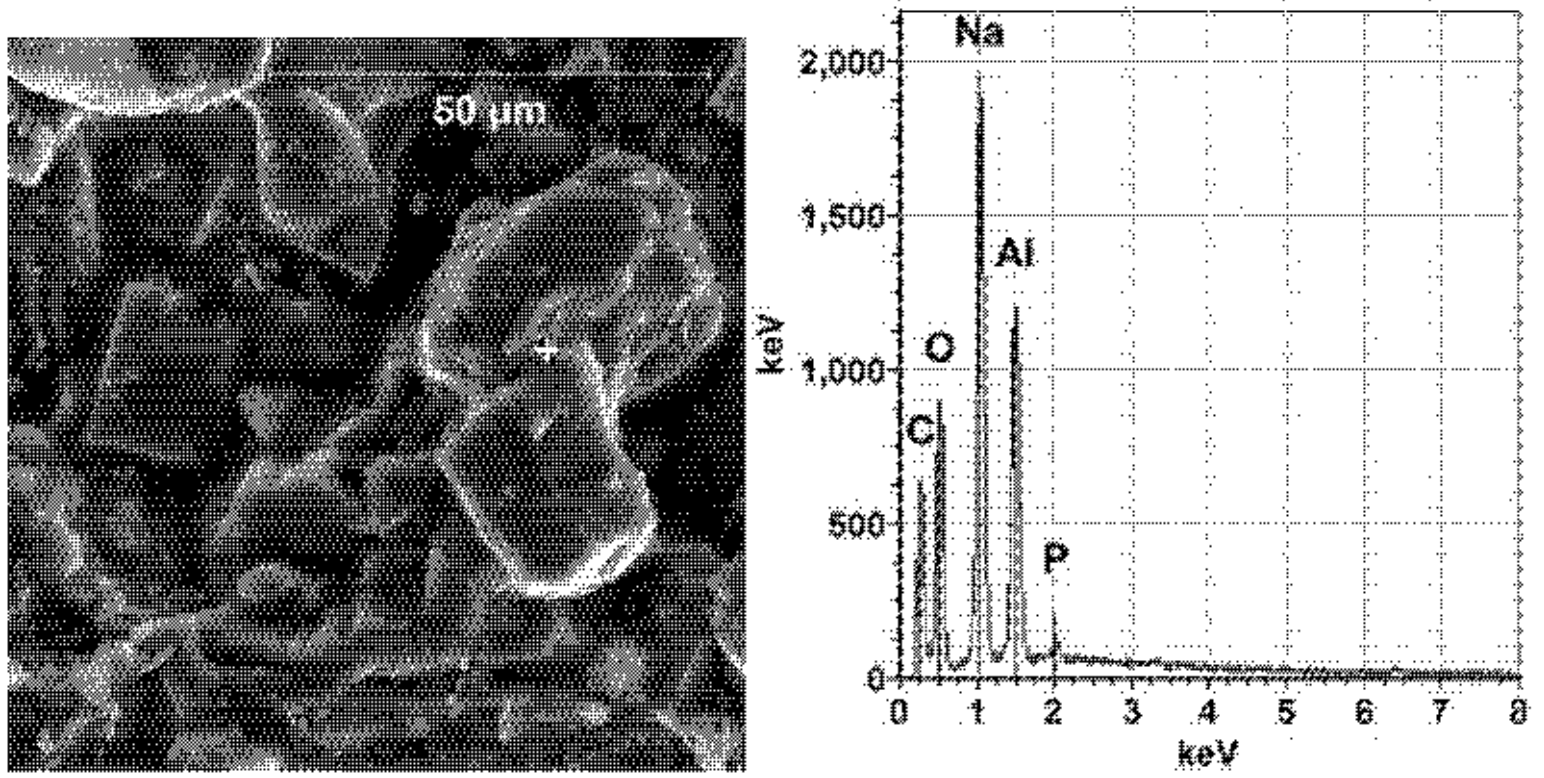

The other phases involved in cementation of the gibbsite aggregates are difficult to determine, because the surrounding gibbsite contributes aluminum X-rays to the EDS spectra. However, 


\section{LAB-RPT-11-00009 REV 0}

some of these phases are efflorescent, occurring as patches on the surface, probably as a result of precipitation from drying pore fluids. Sodium-rich, sodium aluminum-rich, and sodium aluminum phosphorous-rich phases all occur as small efflorescent patches on the surfaces of the gibbsite aggregates. Examples are illustrated in Figures $10 \mathrm{~A}$ and $10 \mathrm{~B}$ as paired SEM images with the EDS spectra.

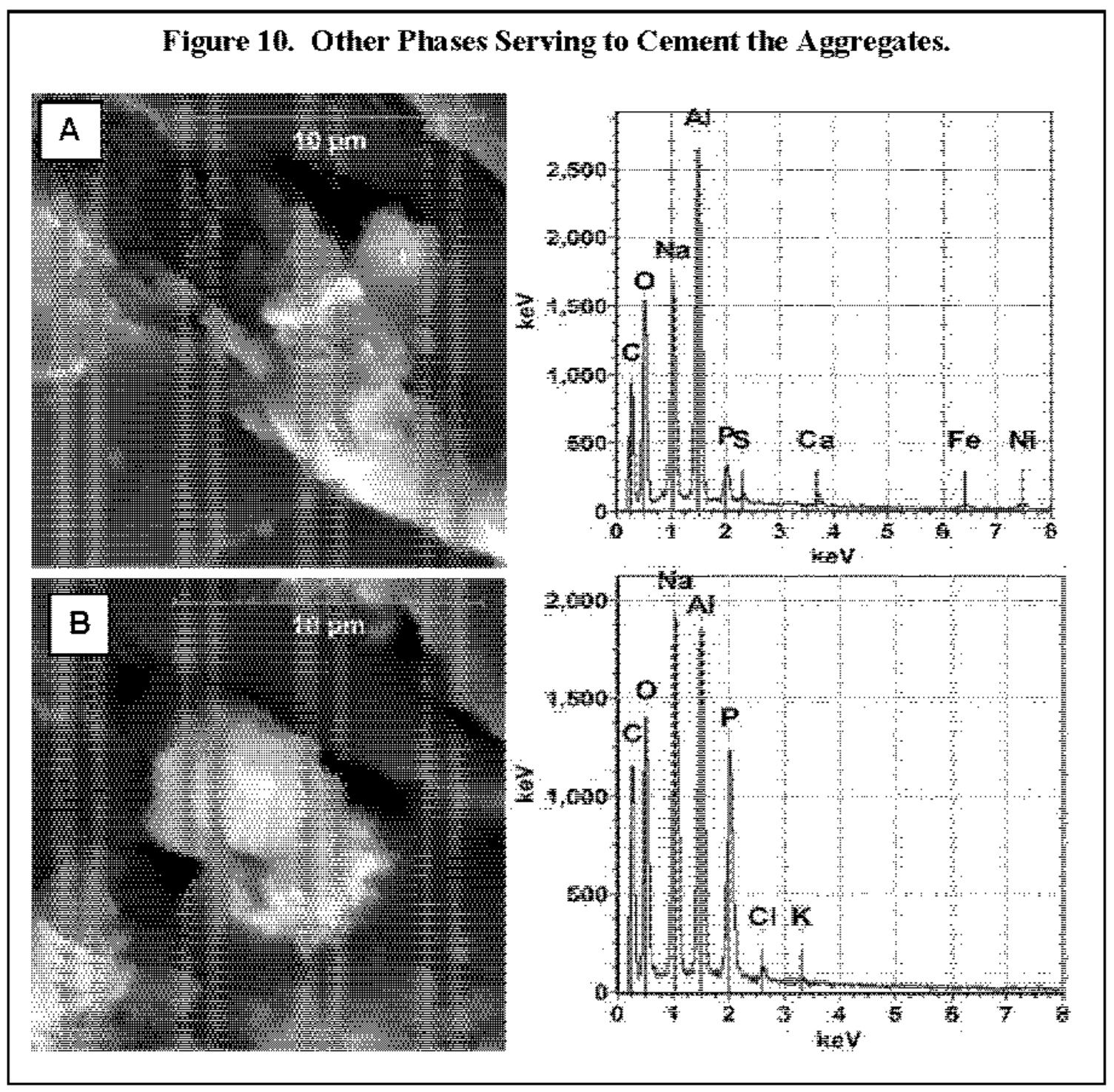

A uranum-rich phase was also found in trace amounts. This phase is probably sodium diuranate $\left(\mathrm{Na}_{2} \mathrm{U}_{2} \mathrm{O}_{7}\right)$ or clarkeite $\left(\mathrm{Na}\left[\mathrm{UO}_{2}\right] \mathrm{O}[\mathrm{OH}] \cdot 0-1\left[\mathrm{H}_{2} \mathrm{O}\right]\right)$. Generally it occurs as patches of randomly oniented crystals, embedded in or coating the gibbsite aggregates (see Figure 11 with both BSE image [left] SE image [center] and EDS spectrum [right]). 
Figure 11. SEM Analys is of S11T00604 Showing a Uranium-Rich Phase.
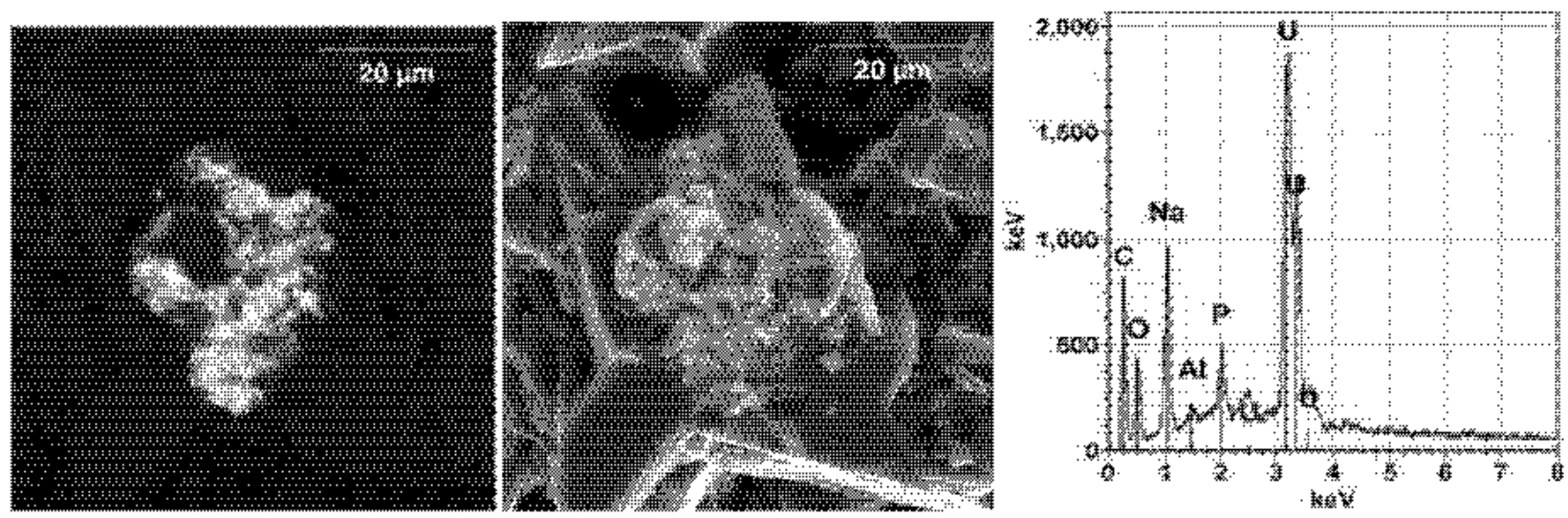

5 GRAB SAMPLE C109-10-1D

Grab sample C109-10-1D, identified visually as a 'bulk sample,' was partially dispersed on a tray and photographed, Figure 12. The contents of the grab sample visually showed a mix of cobbles and fine- to medium-grained particulate. A portion of the grab sample was removed for SPC and labeled as S11T006065. The XRD analysis showed both natrophosphate and gibbsite, with natrophosphate predominating (Figure 13). The percent composition was found to be $26.4 \%$ gibbsite and $73.6 \%$ natrophosphate, which is a relative amount based upon all the crystalline species present in the sample. The SEM analysis was performed on hand-picked grains and showed aggregated gibbsite (Figure 14) and natrophosphate crystals (Figure 15), verifying the XRD results.

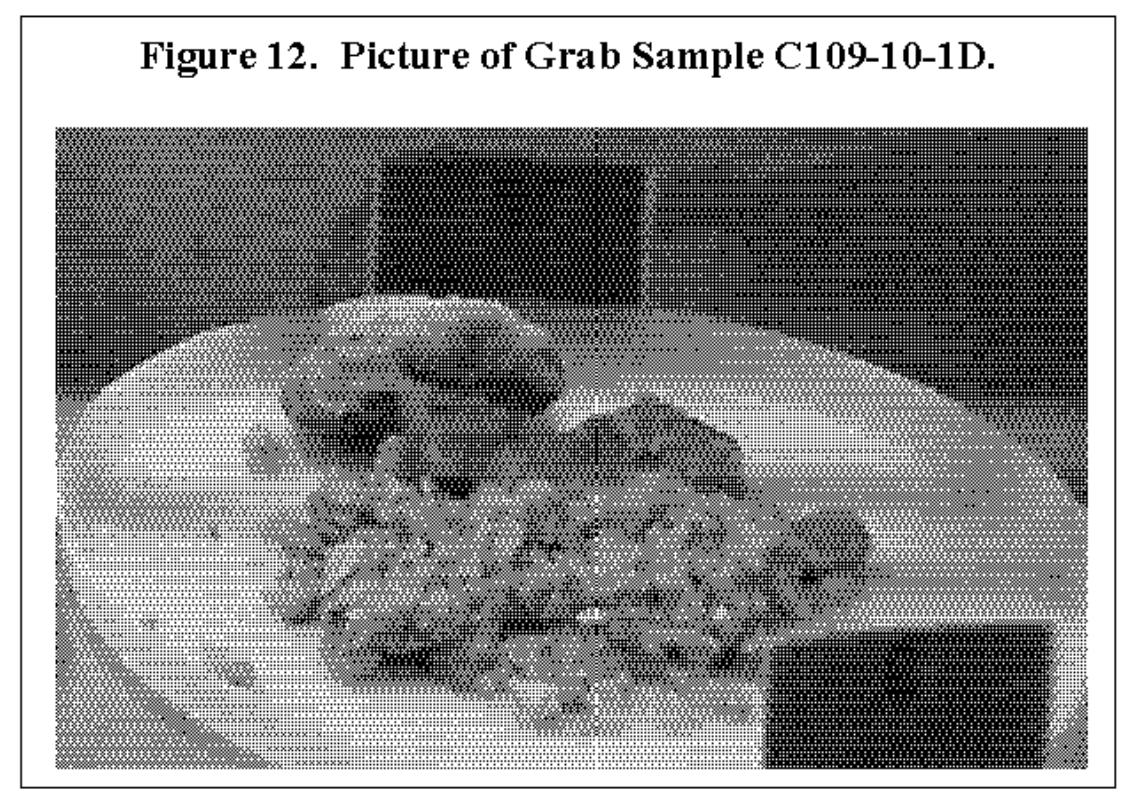


Figure 13. XRD Analysis of \$1 1T006065.

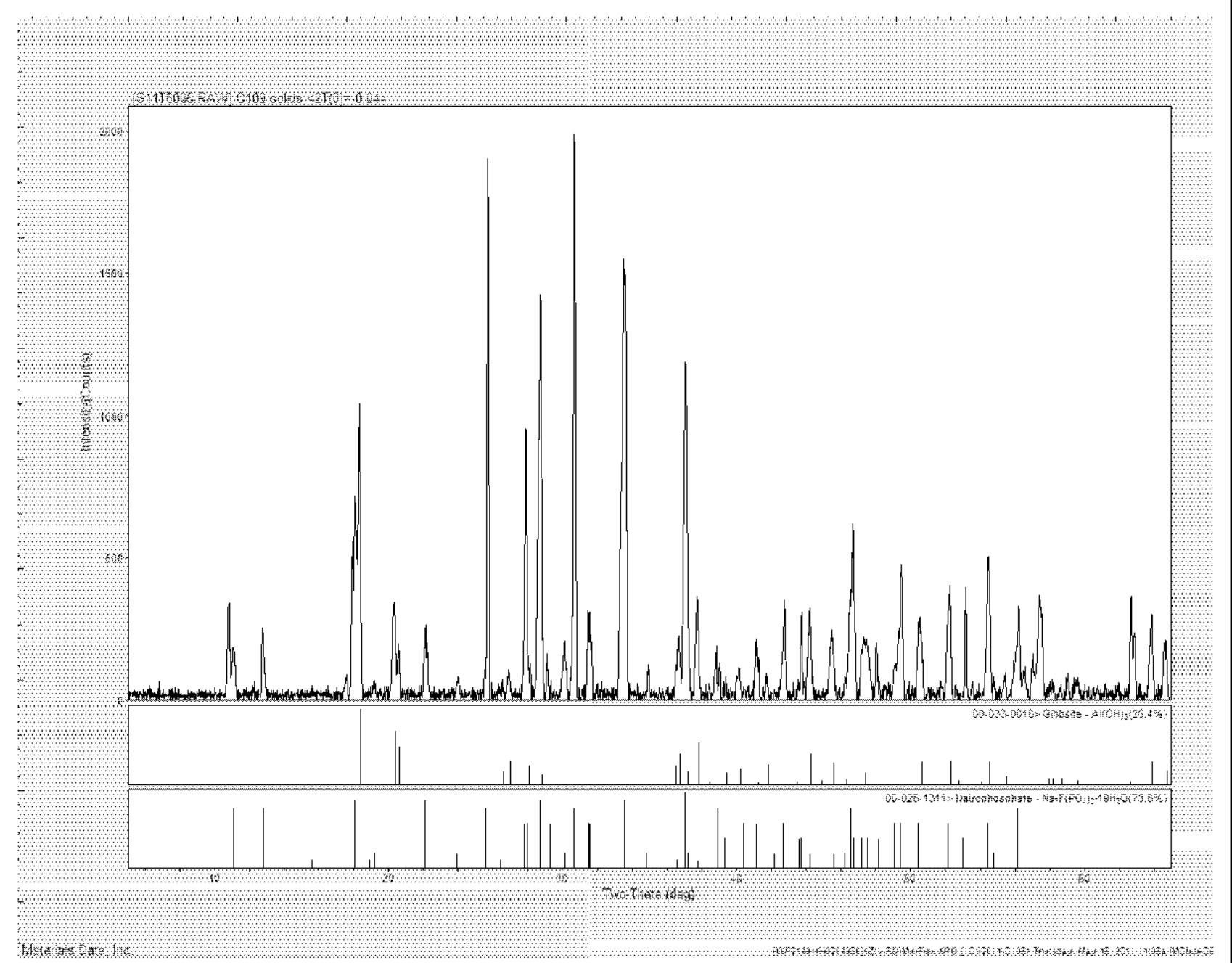


Figure 14. SEM Analysis of a Selected Gibb site Particle from S1lT006065 Bulk Material.
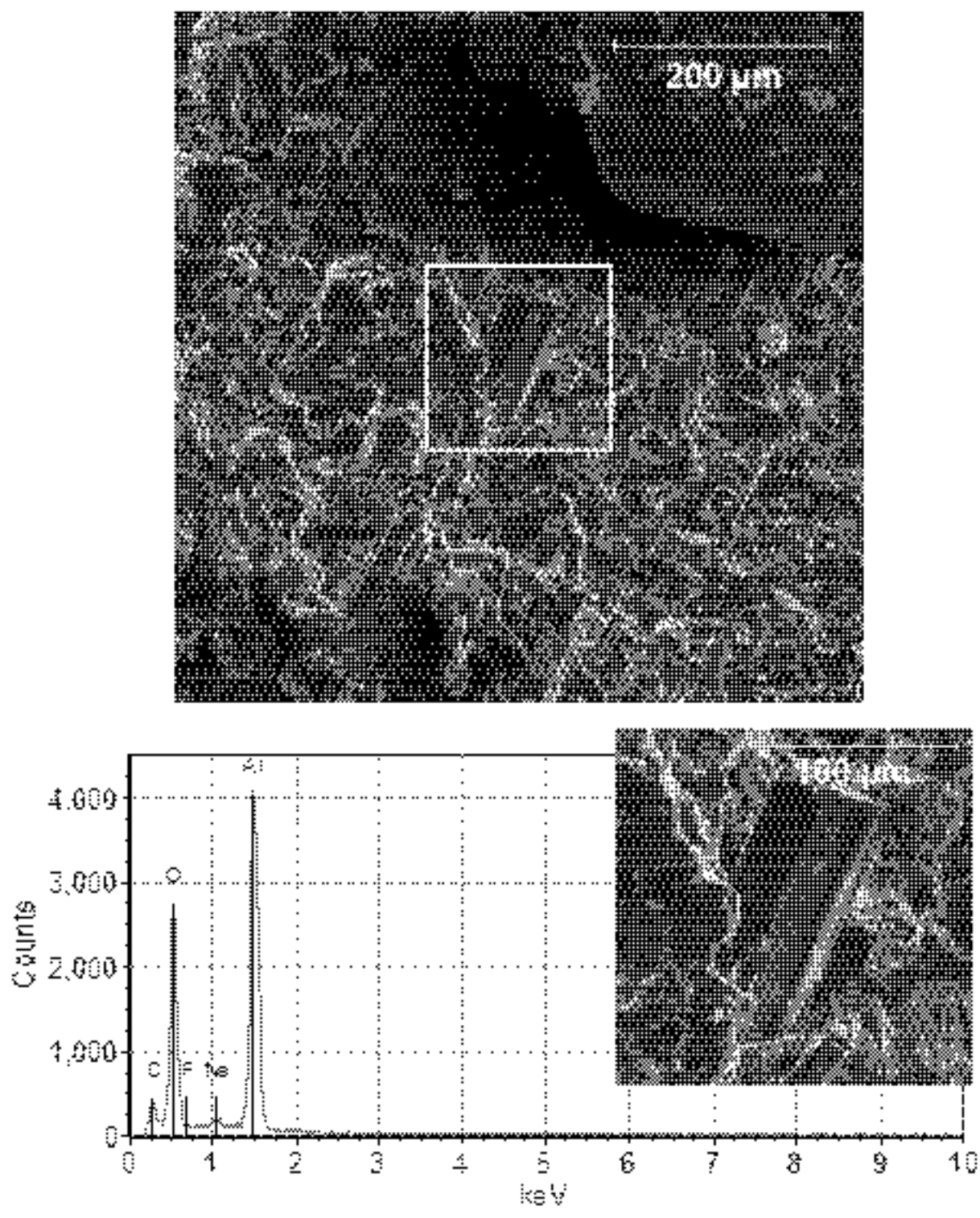


\section{LAB-RPT-11-00009 REV 0}

Figure 15. SEM Analysis of a Selected Natrophosphate Particle from S11 T006065.
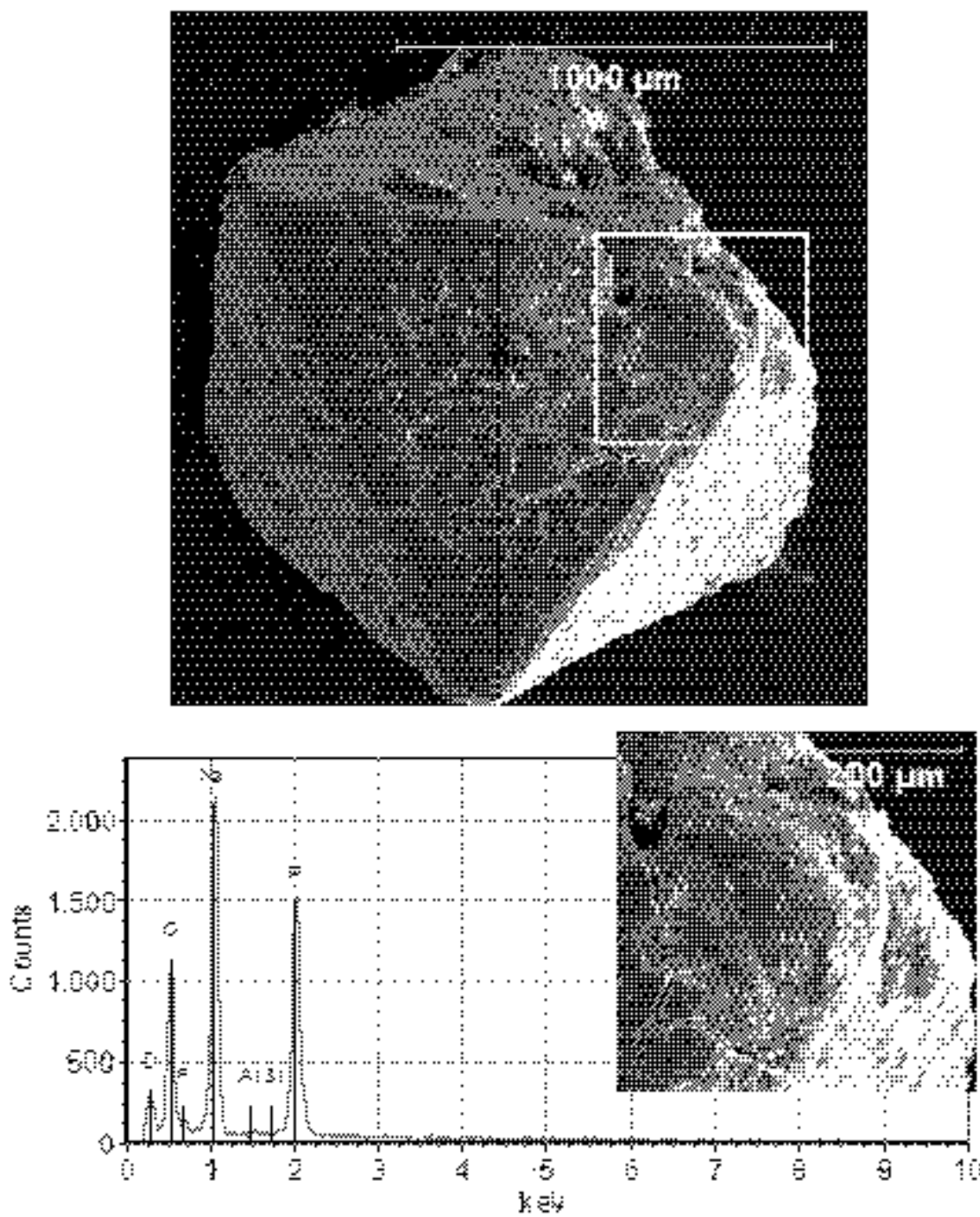


\section{LAB-RPT-11-00009 REV 0}

\section{GRAB SAMPLE C109-10-2A}

Grab sample C109-10-2A was partially dispersed on a tray and photographed, Figure 16. Visually, the contents of the grab sample consisted of a mix of a cobble, gravel, and fine particulate. A cobble from the grab sample was crushed using a mortar and pestle, and fragments of this crushed cobble were sampled for SPC and labeled S11T006066. Several SEM images and EDS spectra were acquired. Figure 17 shows a representative im age and EDS spectrum. The results indicate that the cobble is an aggregate of aluminum-rich phase, probably gibbsite, similar to S11T006064 and S11T006069.

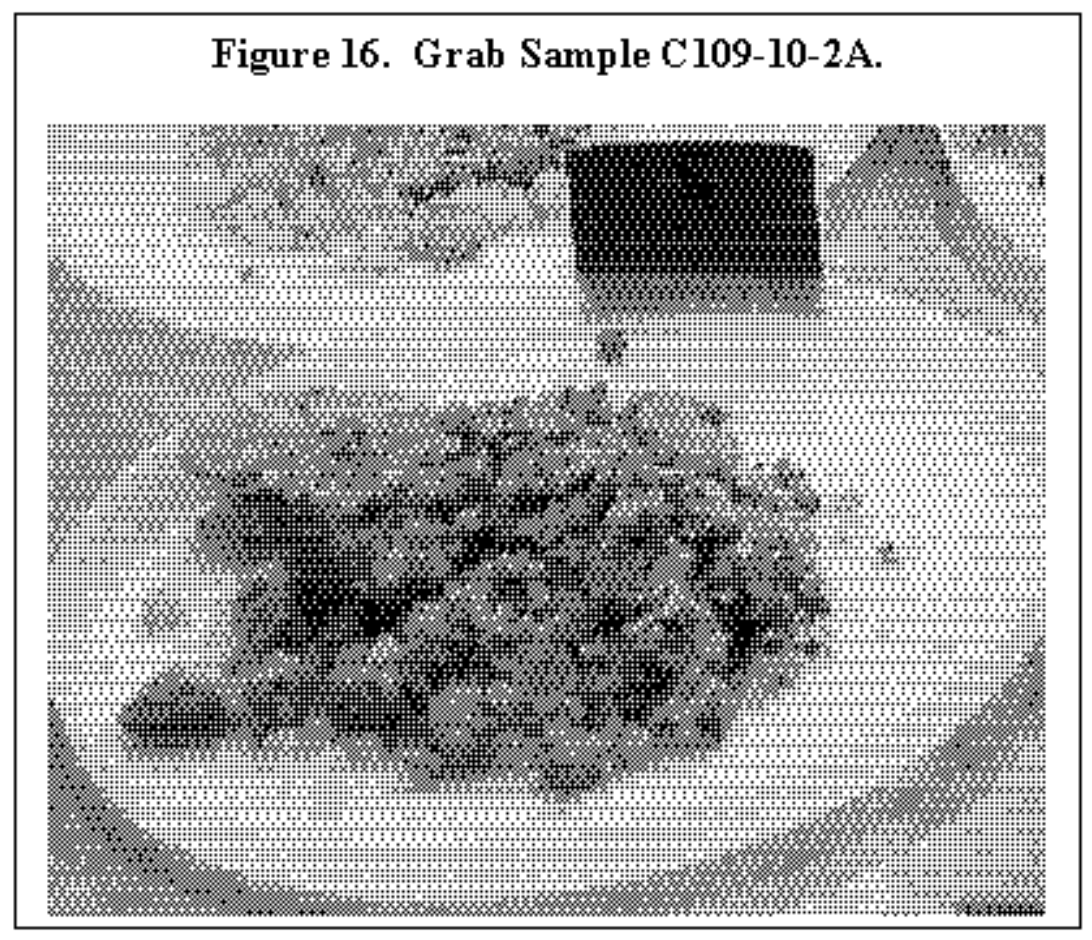

Except for the gibbsite, none of the trace phases was present in the gibbsite aggregates at any appreciable level. This was confirmed by the XRD analysis of the other crushed cobble, S11T006064. Also present at trace level as inclusions and coatings on the aggregates was an amorphous "sludge-like" phase, seen in S11T006066, with a variable chemistry rich in iron, nickel, and lead (Figure 18). Similar material, with a lead-iron association was observed in Tank C-106 (RPP-17158, July 2003), C-108 (LAB-RPT-10-00001, Results of Physicochemical Characterization and Caustic Dissolution Tests on Tank 241-C-108 Heel Solids), and other C Farm residual wastes. 
Figure 17. SEM Analysis of S11T006066 Crushed Cobble.
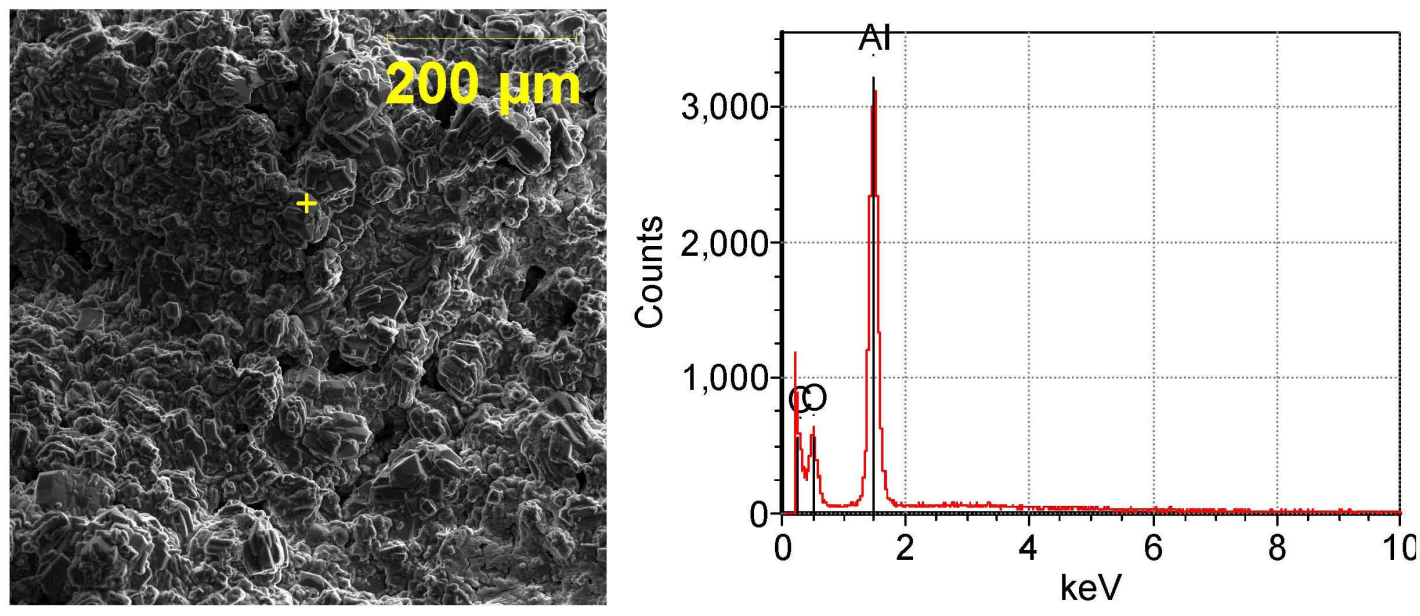

Figure 18. SEM Analysis of an Iron-Rich Sludge Trace Phase.
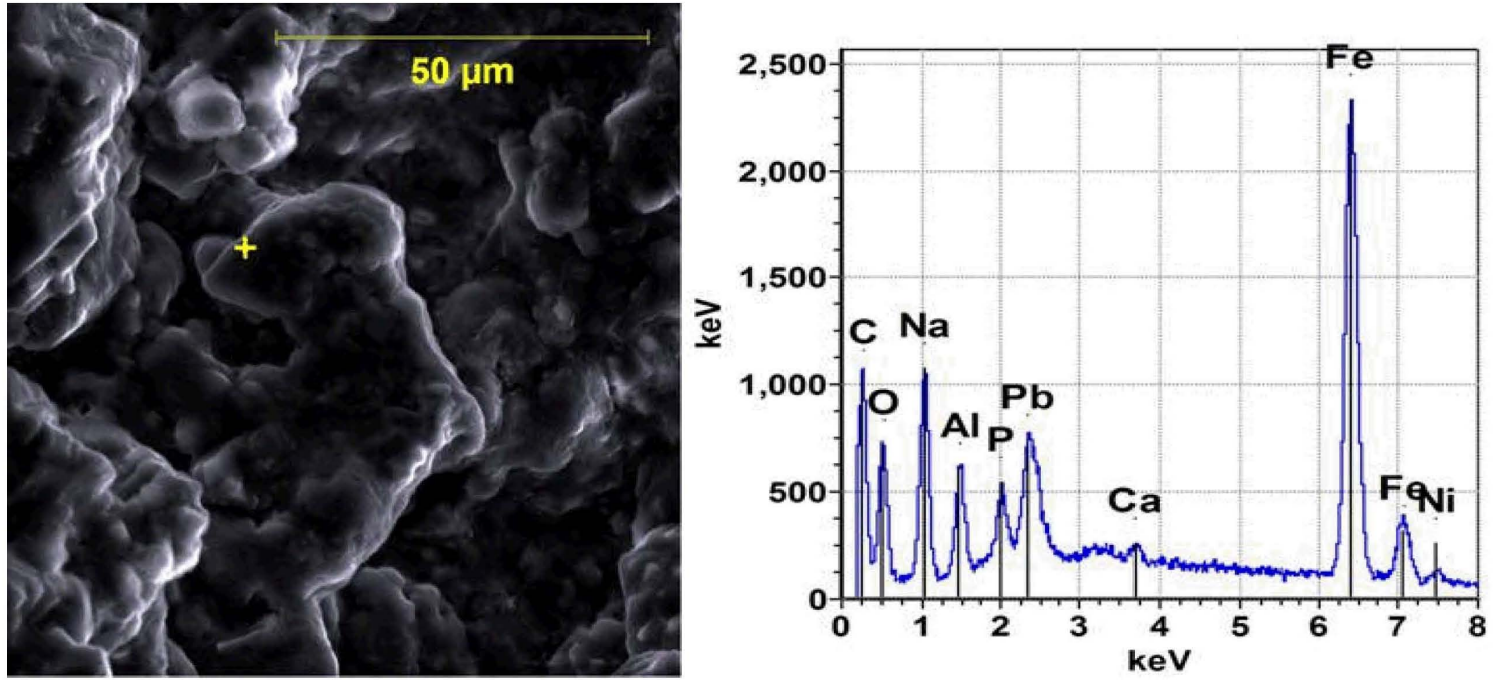


\section{LAB-RPT-11-00009 REV 0}

\section{GRAB SAMPLE C109-10-2C}

Grab sample C109-10-2C was partially dispersed on a tray and photographed, Figure 19. A portion of the grab sample was subsampled for SPC analysis and labeled as S11T006068. The XRD analysis of S11T006068, Figure 20, showed near equal amounts of natrophosphate and gibbsite. The percent composition was found to be $54.5 \%$ gibbsite and $45.5 \%$ natrophosphate, which is a relative amount based upon all the cry stalline species present in the sample. The SEM analysis shows a natrophosphate cemented with an aluminum-rich phase (Figure 21). Another uranium-bearing trace phase, observed on and in the crushed aggregates and hand-picked grains, was also on the particles in sample S11T006068 and appears as distinct euhedral needl e-like crystals, often radially arranged and coating the larger grains (Figure 22). The EDS spectra for this phase are consistent with the sodium diuranate/clarkeite phase.

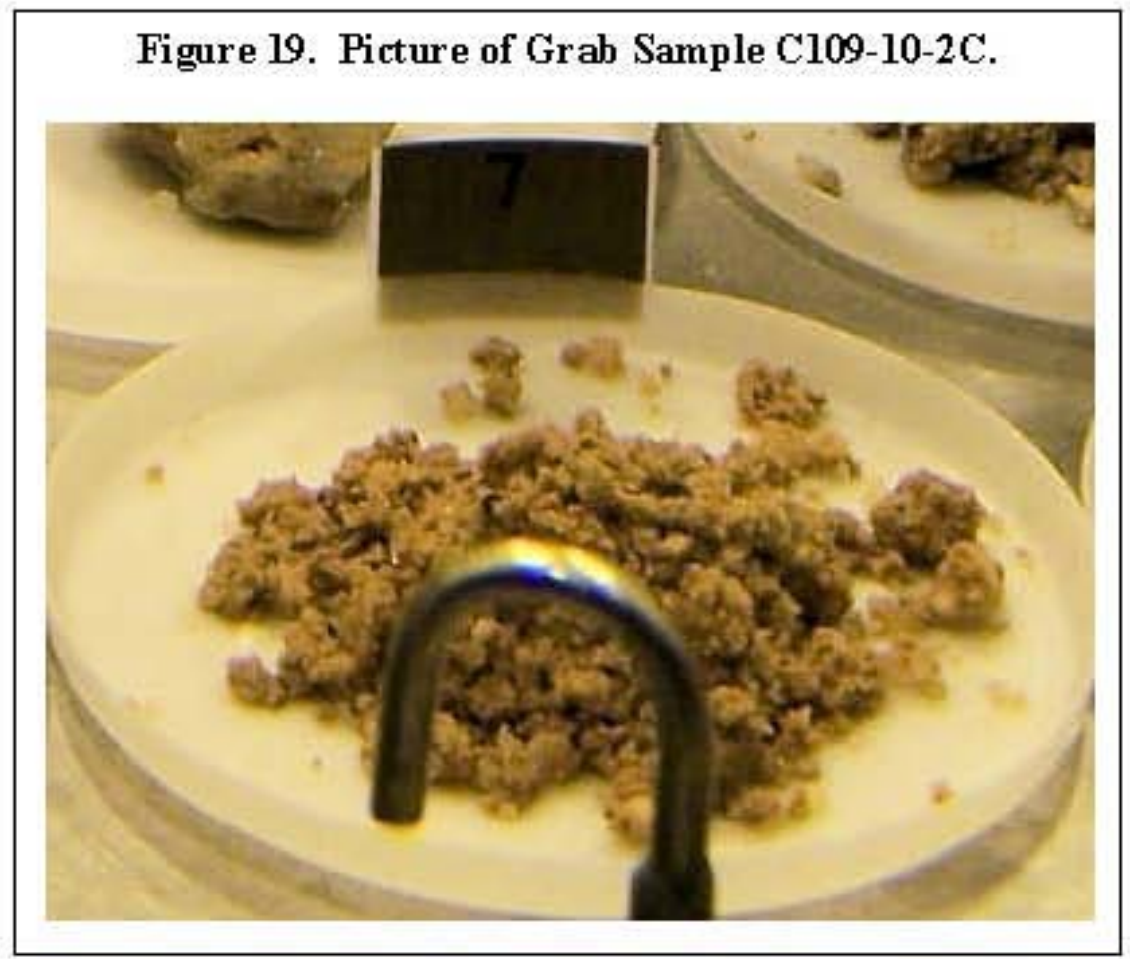


LAB-RPT-11-00009 REV 0

Figure 20. XRD Analysis of S11T006068.

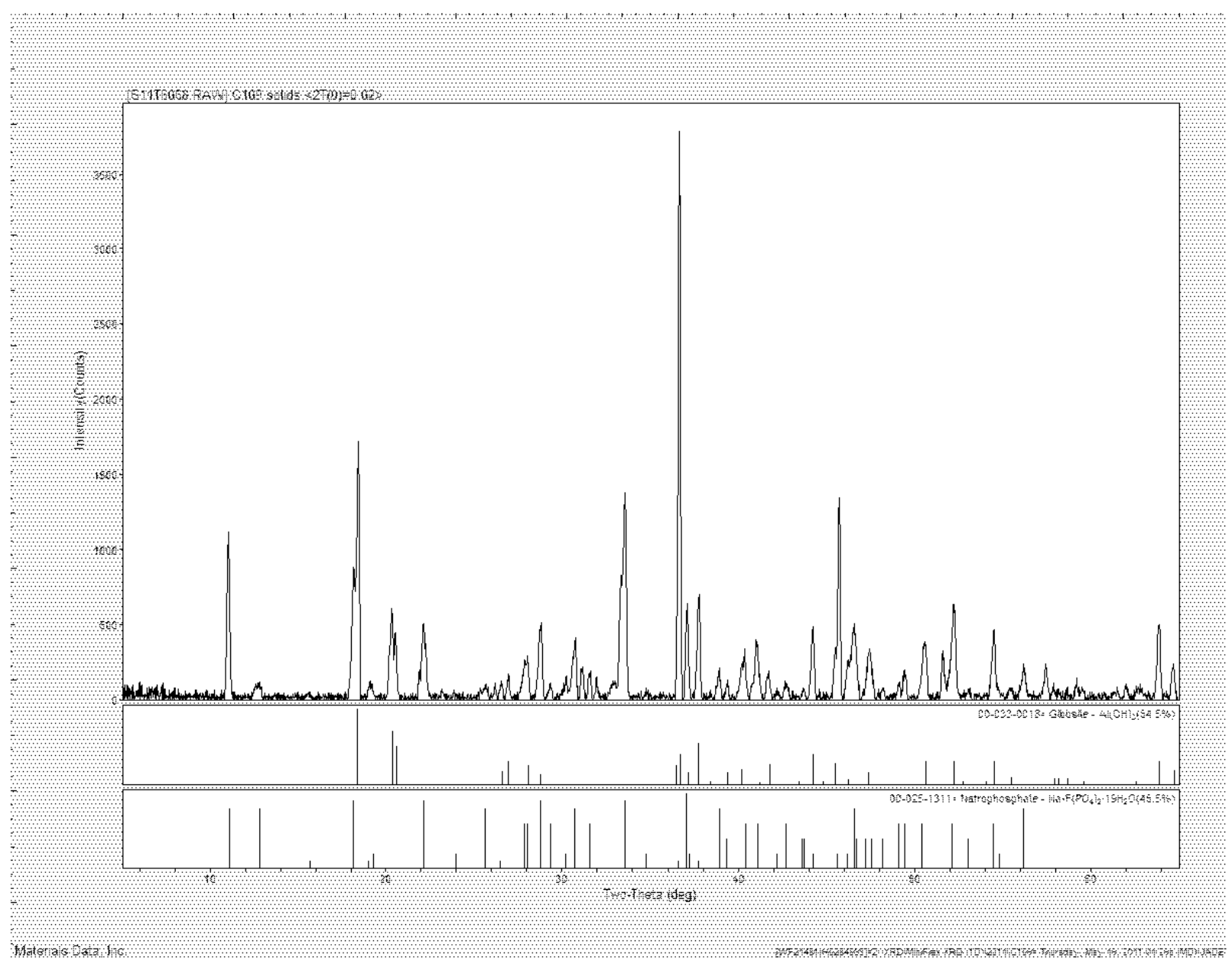




\section{LAB-RPT-11-00009 REV 0}

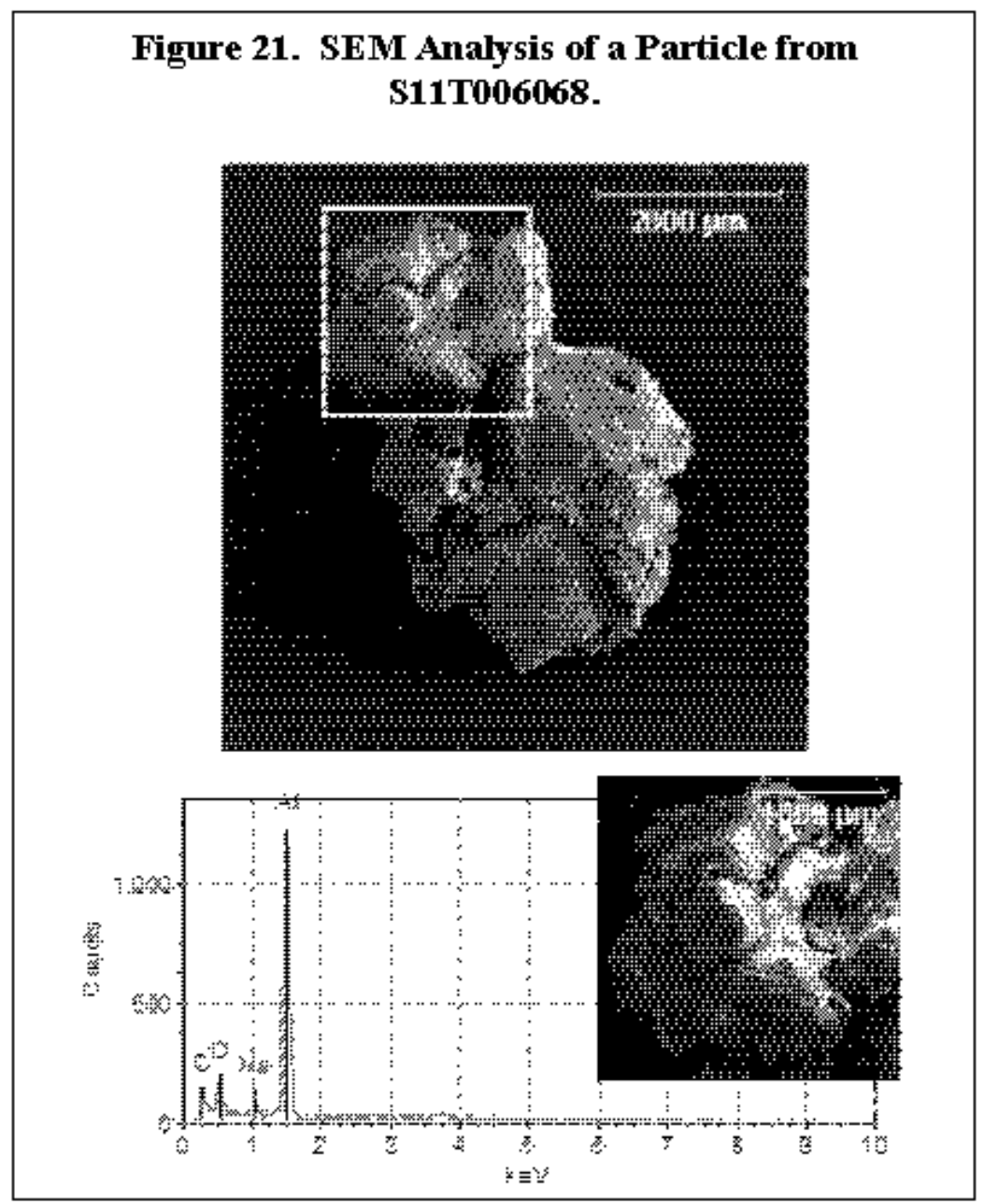

Figure 22. SEM Analysis of a Sodium Diuranate Trace Phase.
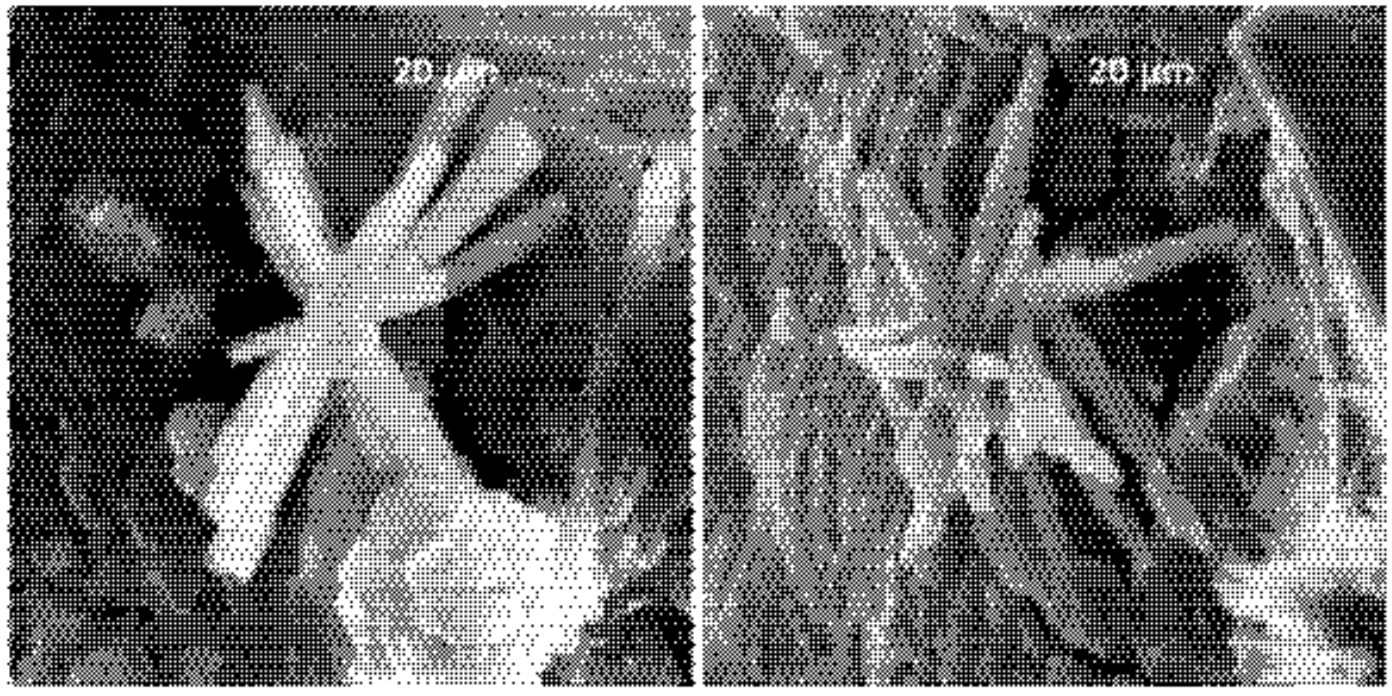


\section{LAB-RPT-11-00009 REV0}

\section{GRAB SAMPLE C109-10-2D}

Grab sample C109-10-2D was partially dispersed on a tray and photographed, Figure 23. The contents were of coarse solids, small cobbles, and fine granular material. A cobble was selected and crushed. Crushed fragments were collected for SPC analysis and labeled S11T006069. The SEM analysis of this sample produced results similar to the other two crushed cobbles samples, S11T006064 and S11T006066, showing aggregates of an aluminum oxide phase (identified as gibbsite in the XRD analysis of S11 T006064). The aggregates exhibited a moderate amount of open pore space (Figure 24). They also contained phases other than gibbsite. The EDS image in Figure 24 was taken by scanning the region inside the box in the left-hand image. The EDS spectrum is dominated by the aluminum from the gibbsite. However, sodium and phosphorous are also present on this surface.

Scattered throughout the gibbsite aggregates are patches of the natrophosphate. This phase occurs as individual crystals, imbedded in the aggregate. They usually appeared to be partially dissolved (Figure 25).

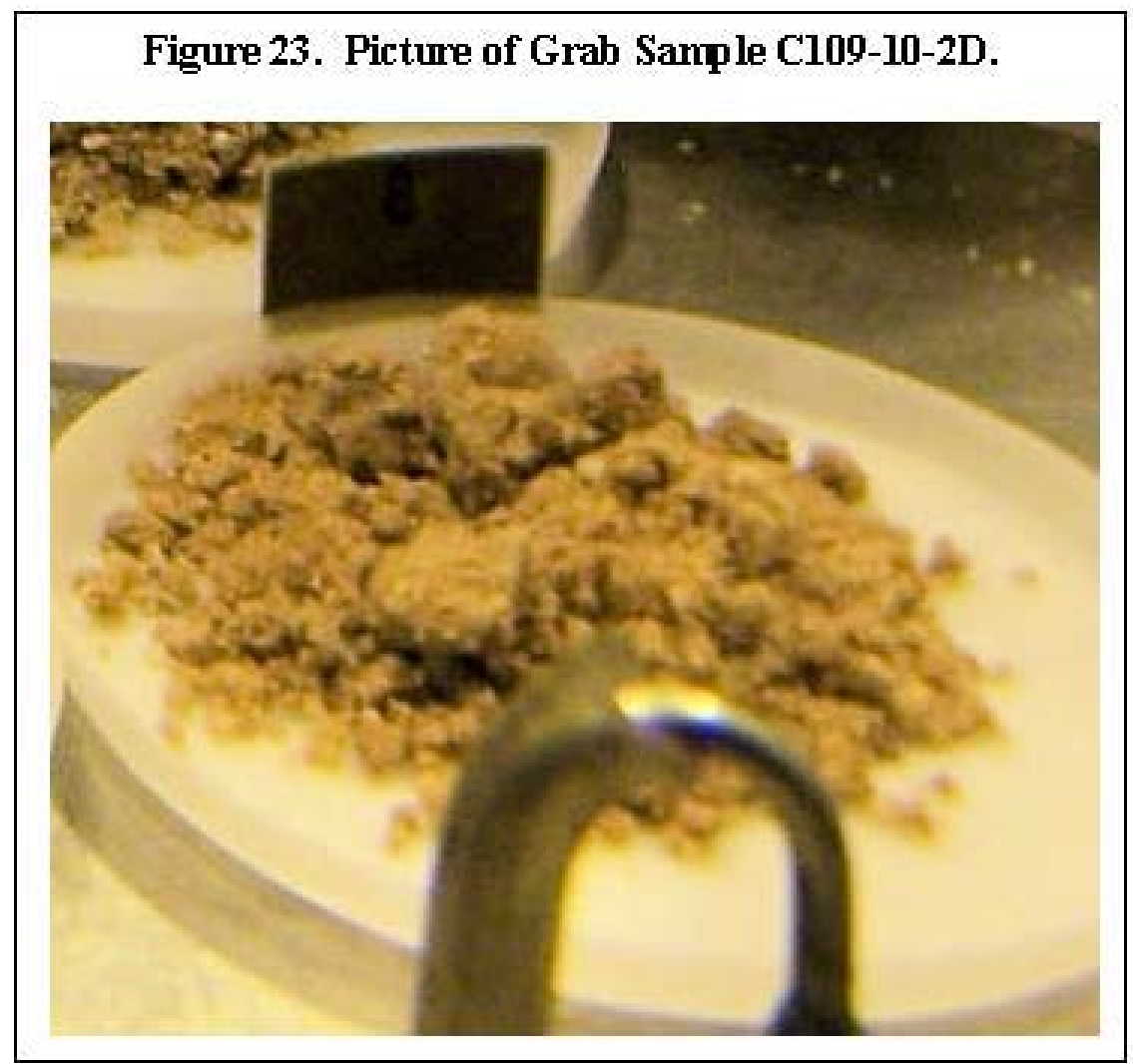



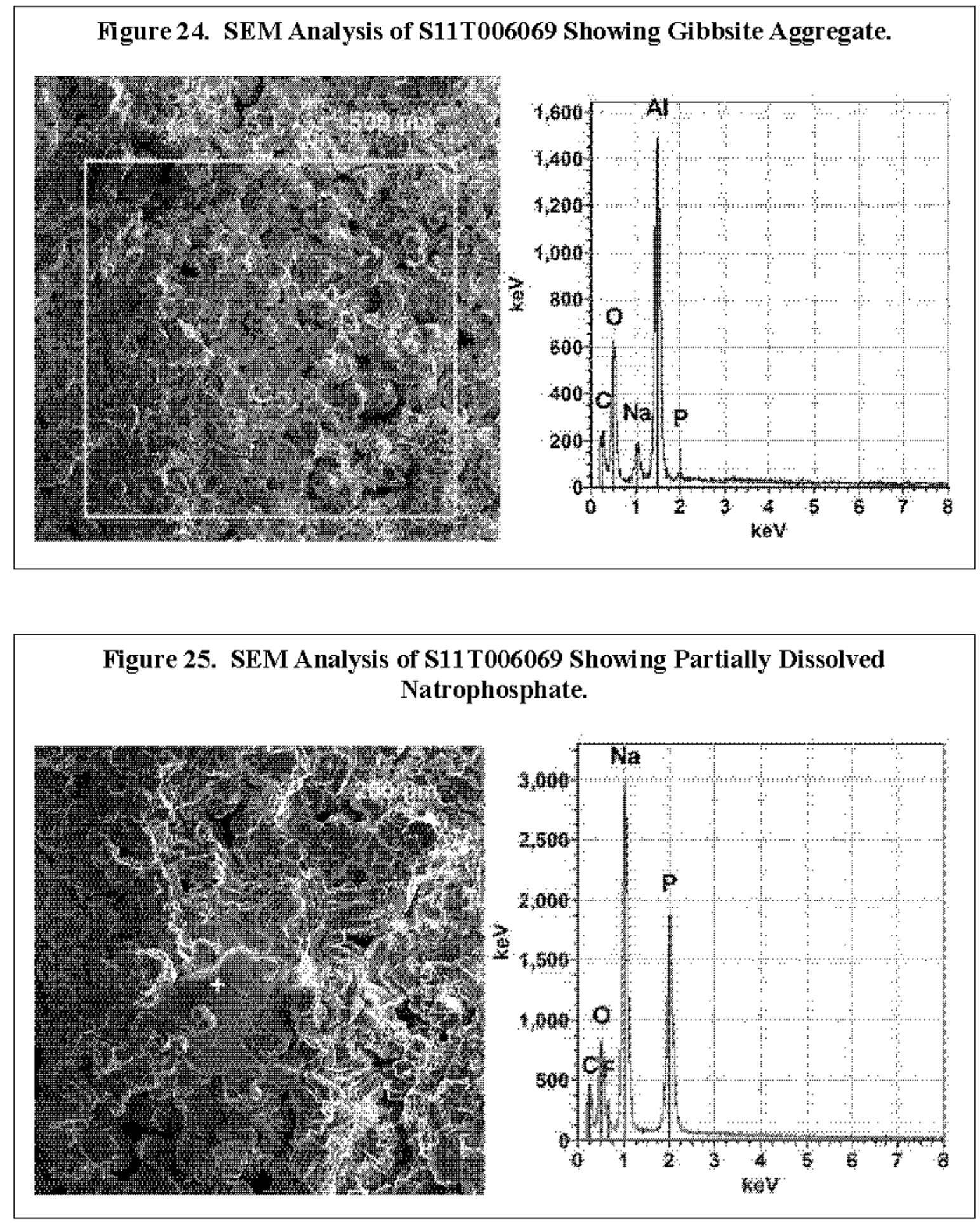


\section{LAB-RPT-11-00009 REV 0}

\section{COMPOSITE}

In order to perform a dissolution study on the retrieval of the hard heel from tank C-109, a composite was created based on the SPC results of the grab samples. The composite was crushed and homogenized, and a photo was acquired, Figure 26. This composite was subsampled for SPC analysis, and this sample was labeled S11T009482.

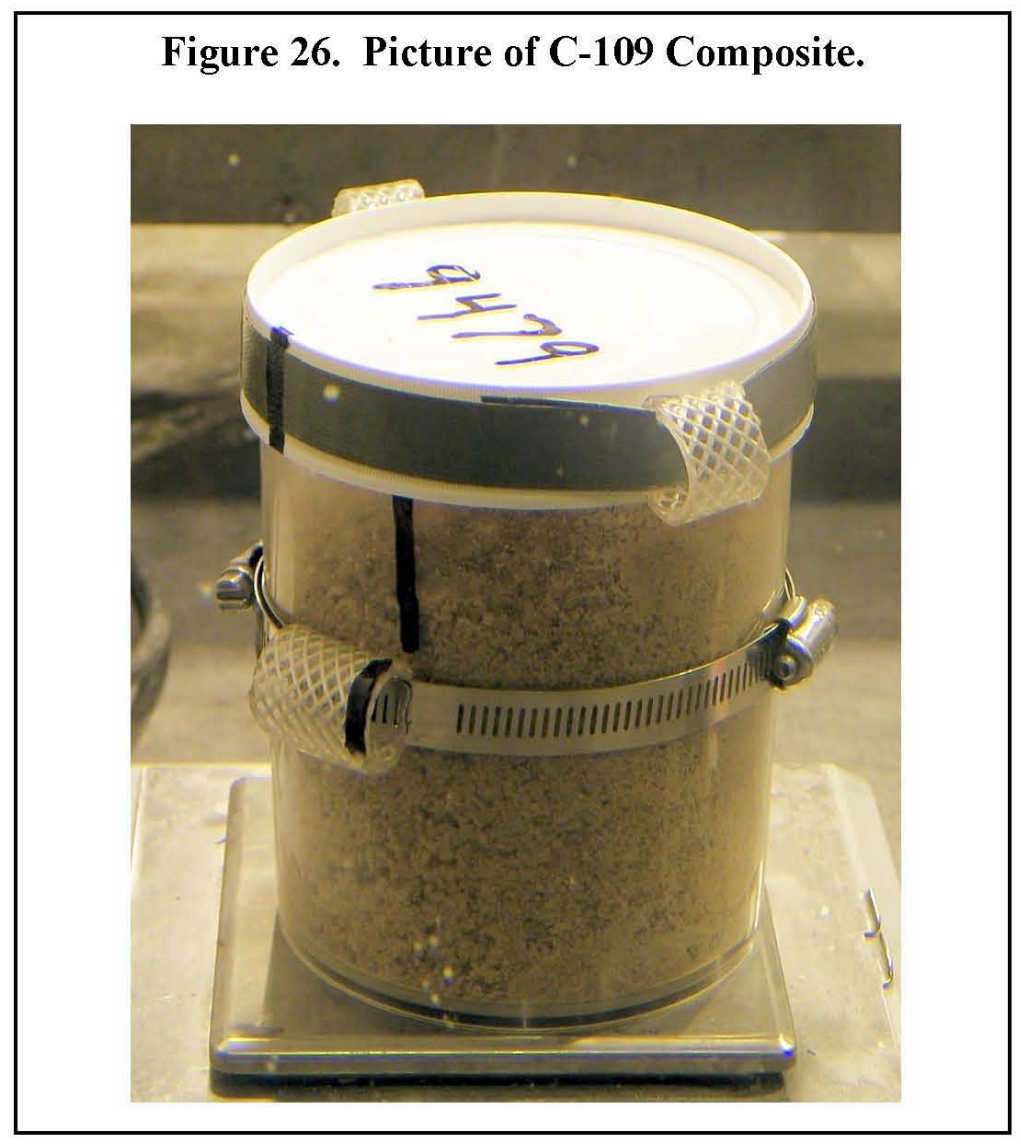

The XRD analysis of S1 1T009482 indicated a larger concentration of gibbsite than natrophosphate (Figure 27). The percent composition was found to be $83.5 \%$ gibbsite and $16.5 \%$ natrophosphate, which is a relative amount based upon all the crystalline species present in the sample. This is slightly more gibbsite than is indicated by the chemical analysis reported in RPP-RPT-50883. Those results indicate that the composite consists of approximately $2 / 3$ gibbsite and 1/3 natrophosphate. The difference in these two numbers could be a result of the composite not being truly homogenous.

A SEM specimen of S11T009482 was made using an acetone dispersion method. Acetone was chosen since the composite was expected to be subjected to a water dissolution procedure, and acetone would minimize dissolution during the sample preparation, retaining the native form and composition. The dispersion was accomplished by first using a glass stirring rod to further crush 


\section{LAB-RPT-11-00009 REV 0}

the sample in the vial. A $45 \mathrm{~mm}$ diameter, $0.4 \mu \mathrm{m}$ Nucleopore polycarbonate filter was placed in the vacuum filtration apparatus, and the funnel was filled with $\sim 10 \mathrm{~mL}$ of acetone. A small portion of S11T009482 was transferred to the funnel using a microspatula, and the vacuum was immediately turned on removing the acetone and pulling the sample onto the filter surface. The filter was allowed to air dry. A small square of the loaded filter was then cut and affixed to a carbon planchet and SEM stub using carbon glue. The specimen was carbon coated in a Cressington 108 carbon coater and loaded into the SEM for analysis.

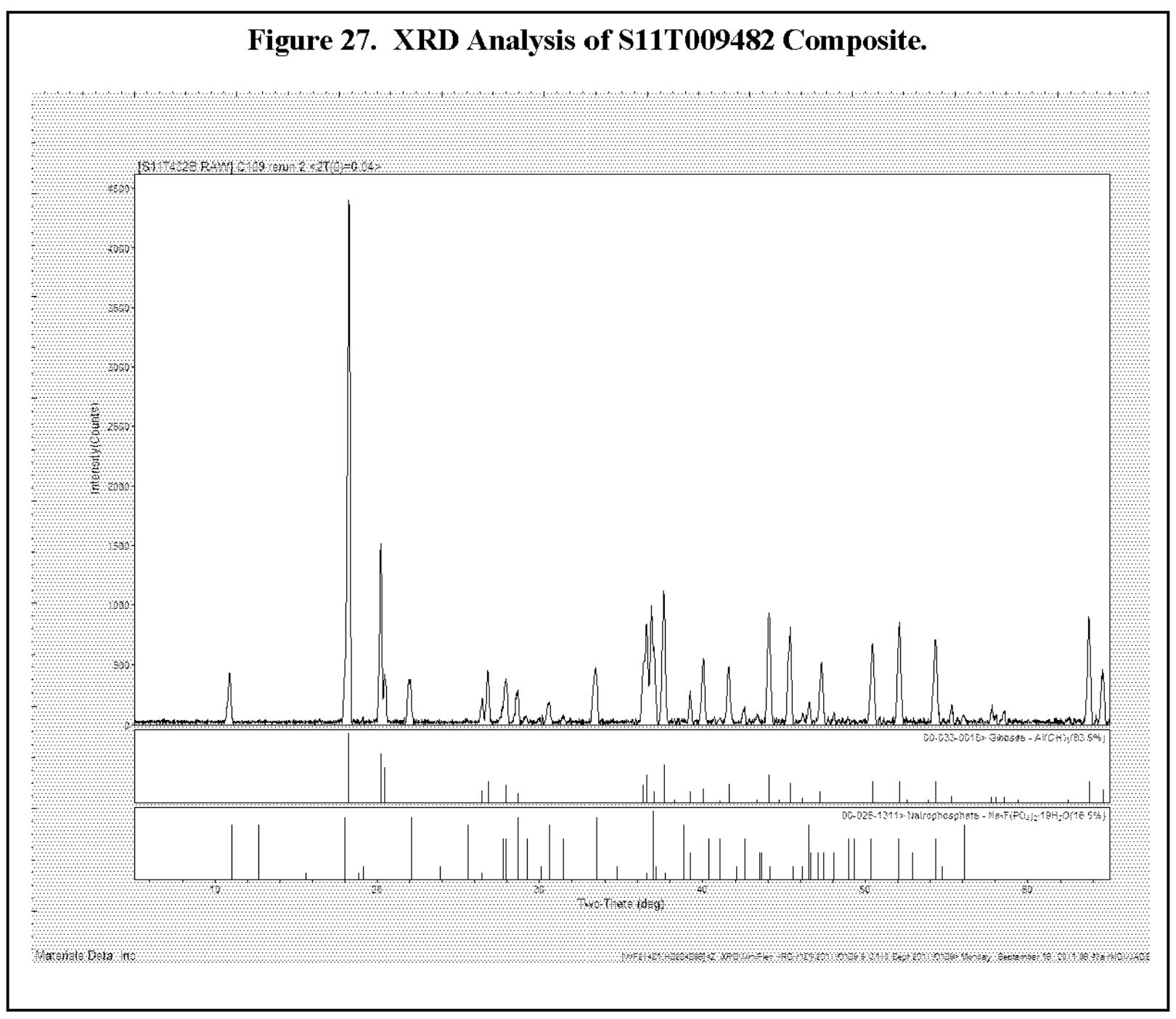

Initial lower magnification imaging of the sample using SE and BSE shows a mix of sizes of single particle and aggregates up to $\sim 100 \mu \mathrm{m}$, Figure 28A. The BSE image, Figure $28 \mathrm{~B}$, reveals that the phases contain lighter elements (darker areas) interspersed with very minor, small particle phases containing heavier elements (brighter areas). 
Figure 28. SE and BSE Images Showing Particle Size and Relative Elemental Mass.
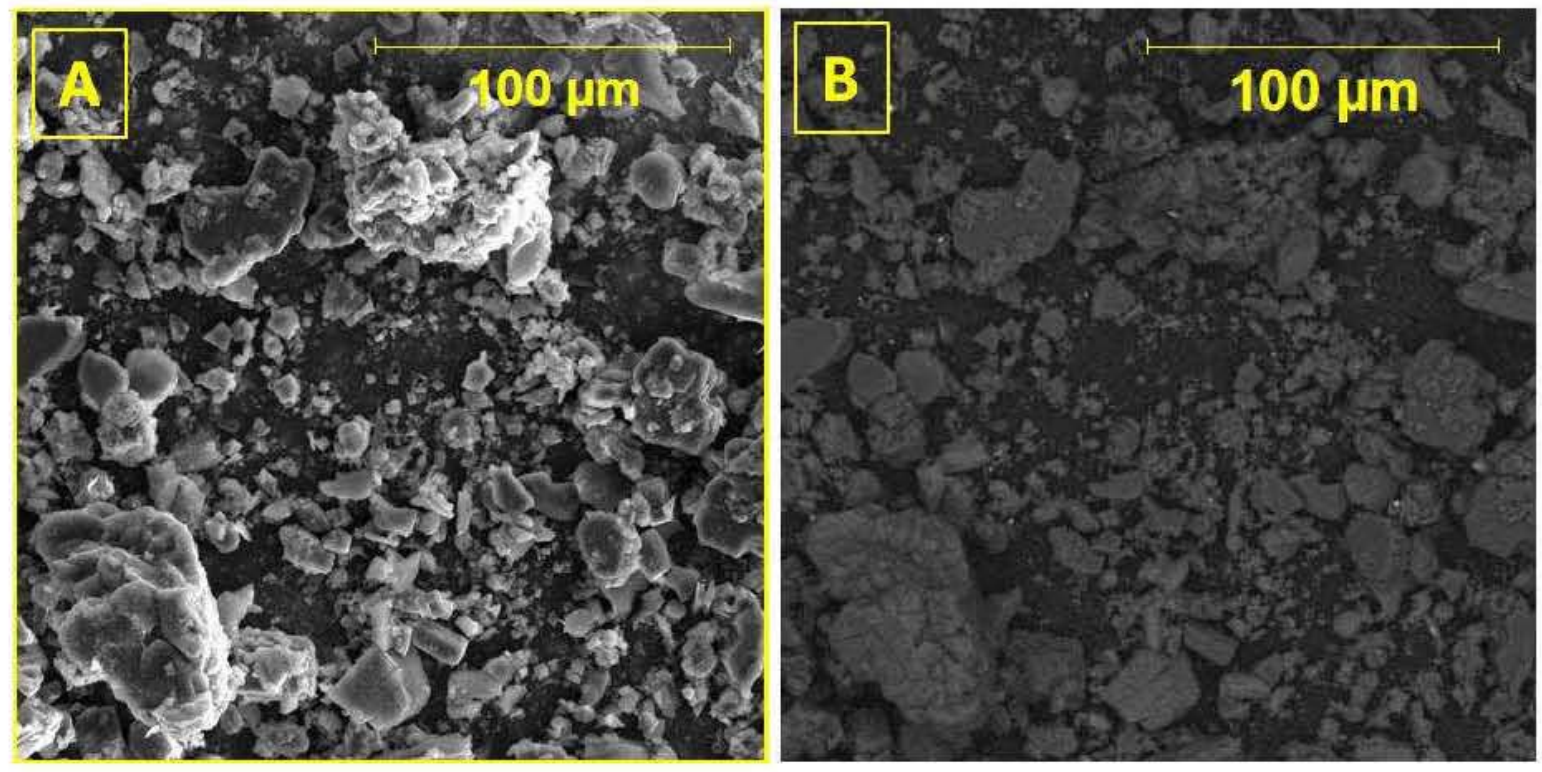

Further EDS analysis of selected particles from Figure 28 shows the elemental components of the different phases in the composite, Figure 29. 
Figure 29. SE Images and EDS Spectra of Various Particles.
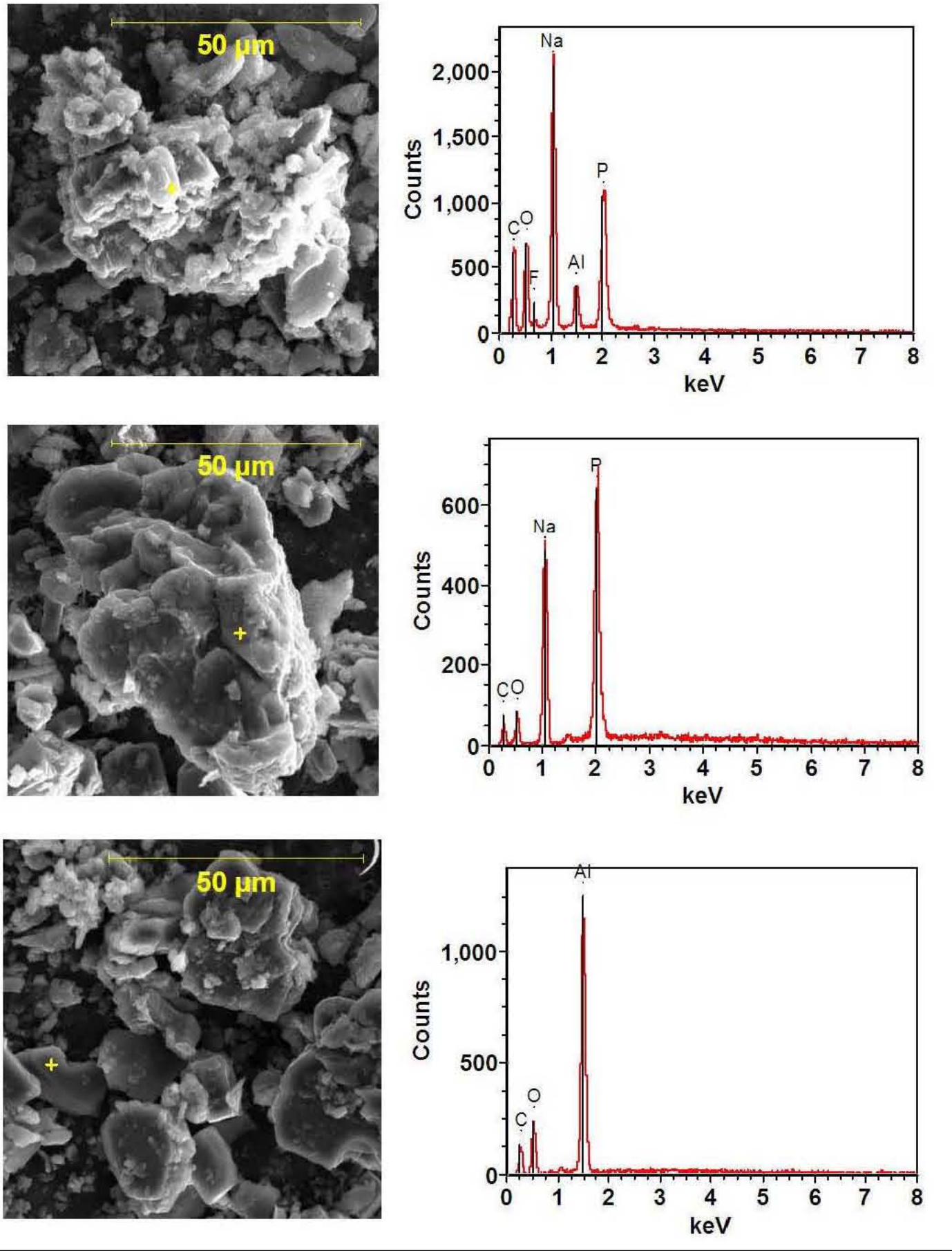

The top image shows an aggregate of a sodium fluoride phosphate, natrophosphate, with some small aluminum oxide particles coating the surface or intermixed in the aggregate. The middle image is a similarly sized particle but mainly sodium phosphate, and the lower image shows a smaller particle of subhedral aluminum oxide (possibly gibbsite). 


\section{LAB-RPT-11-00009 REV 0}

Another section of the SEM specimen was analyzed which contained particles and aggregates up to $\sim 50 \mu \mathrm{m}$ (Figure 30). An SE image at the top of the figure shows the particles. The lower SE images are from different areas of the top image and are coupled with EDS spectra (the yellow cross showing where the EDS spectrum was acquired).

The particle in Figure $30 \mathrm{~A}$ is a euhedral aluminum oxide (possibly gibbsite). The aggregate particle in $30 \mathrm{~B}$ is natrophosphate with some aluminum phase also present. The elongated crystal in $30 \mathrm{C}$ is possibly a sodium aluminum phosphate along with the particle in $30 \mathrm{D}$. Since the XRD did not detect a sodium aluminum phosphate, this could be either a trace phase, a solid solution, amorphous, or a coating. The particle in $30 \mathrm{E}$ is another aluminum oxide of the same phase in $30 \mathrm{~A}$. Figure $30 \mathrm{~F}$ shows a smaller aggregate particle which is another natrophosphate with a lower level of aluminum phase coating. 
Figure 30. SE Images and EDS Spectra of Various Smaller Particles.
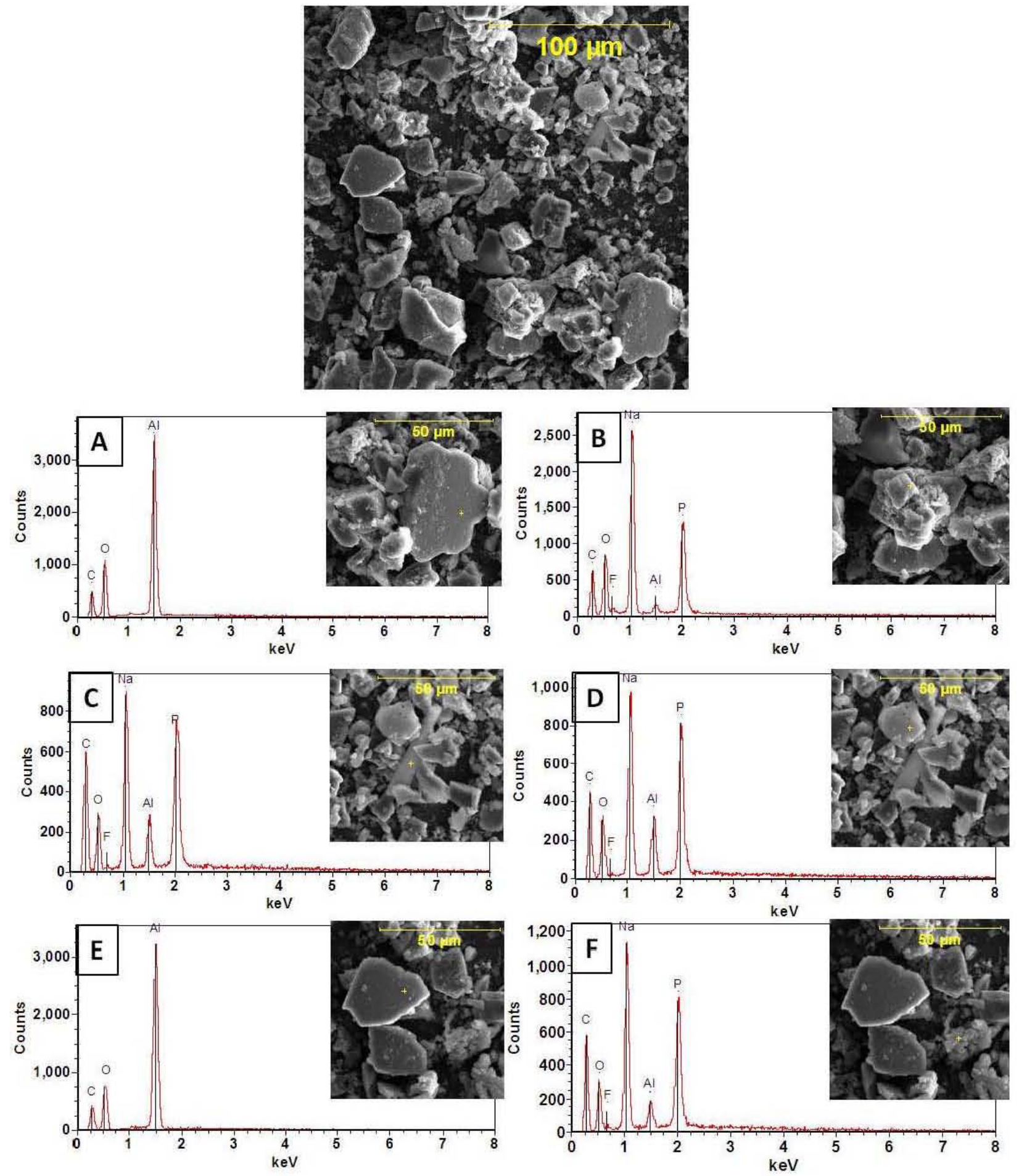
In general, the vast majority of particles analyzed in the composite sample were either an aluminum oxide or a sodium fluoride phosphate. Interspersed in this mix were small particles that showed brightly in BSE images like the one displayed in Figure 31. Further analysis of these small, minor phases showed them to be rich in sodium and uranium.

Figure 31. BSE Image and EDS Spectrum of a Minor Uranium-Rich Phase.
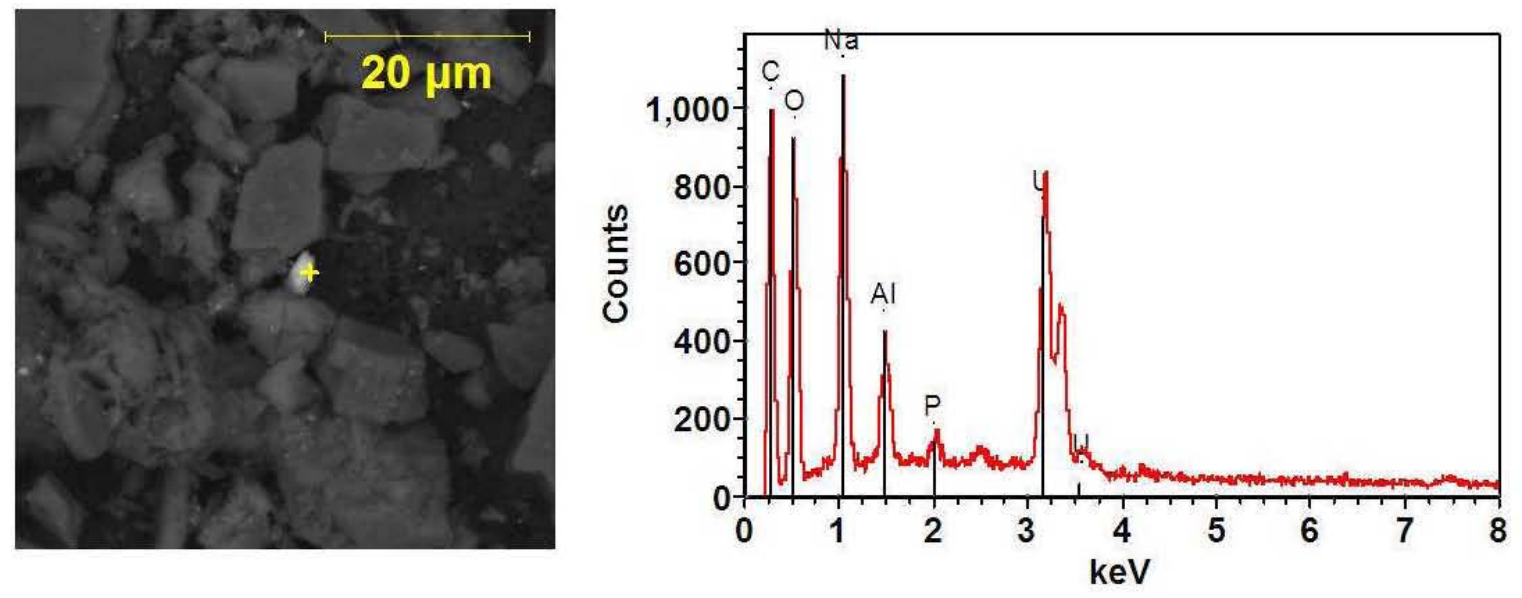

\section{References}

ATS-LAB-PLN-11-00006, 2011, Test Plan for Tank 241-C-109 Heel Solids Characterization and Dissolution Testing, Rev. 0, Washington River Protection Solutions LLC, Richland, Washington.

LAB-RPT-10-00001, 2010, Results of Physicochemical Characterization and Caustic Dissolution Tests on Tank 241-C-108 Heel Solids, Rev. 0, Washington River Protection Solutions LLC, Richland, Washington.

RPP-17158, Rev. 0, Bechtold, D.B., Cooke, G.A., Herting, D.L., Person, J.C. Viswanath, R.S. and Warrant, R.W., 07/10/2003, Laboratory Testing of Oxalic Acid Dissolution of Tank 241-C106 Sludge, Fluor Hanford.

RPP-PLAN-47927, 2010, Sampling and Analysis Plan for Waste Solids in Tank 241-C-109 After Sluicing, Rev. 0, Washington River Protection Solutions LLC, Richland, Washington.

RPP-RPT-50883, 2011, Final Report for the Analysis of Waste Solids in Tank 241-C-109, 2011, Rev. 0, Advanced Technologies and Laboratories International, Inc., Richland, Washington. 


\section{Electronically Approved by:}

UserName: Page, Jason (h2841343)

Title:

Date: Friday, 16 December 2011, 09:07 AM Pacific Time

Meaning: Approved by the author or delegate

UserName: Pestovich, John (h0284989)

Title:

Date: Friday, 16 December 2011, 09:46 AM Pacific Time Meaning: Additional approval obtained

UserName: Cooke, Gary (h0410221)

Title: APD Chemist

Date: Monday, 19 December 2011, 10:00 AM Pacific Time Meaning: Additional approval obtained

UserName: Nguyen, Duc (h0051515)

Title: Flowsheet and Process Models

Date: Monday, 19 December 2011, 10:46 AM Pacific Time Meaning: Approved by the customer or delegate

UserName: Hardy, Don (h0085161)

Title: Laboratory Facilities Manager

Date: Monday, 19 December 2011, 02:37 PM Pacific Time Meaning: Approved by the Facility Manager or delegate 


\section{Electronically Approved by:}

UserName: Seidel, Cary (h0009079)

Title: APD Manager

Date: Tuesday, 20 December 2011, 10:42 AM Pacific Time

Meaning: Approved by the Group Manager or delegate 